\title{
Review
}

\section{Bio-recognition and functional lipidomics by glycosphingolipid transfer technology}

\author{
By Takao TAKI ${ }^{* 1, \dagger}$
}

(Communicated by Kunihiko SuzukI, M.J.A.)

\begin{abstract}
Through glycosphingolipid biochemical research, we developed two types of transcription technologies. One is a biochemical transfer of glycosphingolipids to peptides. The other is a physicochemical transfer of glycosphingolipids in silica gel to the surface of a plastic membrane. Using the first technology, we could prepare peptides which mimic the shapes of glycosphingolipid molecules by biopanning with a phage-displayed peptide library and antiglycosphingolipid antibodies as templates. The peptides thus obtained showed biological properties and functions similar to those of the original glycosphingolipids, such as lectin binding, glycosidase modulation, inhibition of tumor metastasis and immune response against the original antigen glycosphingolipid, and we named them glyco-replica peptides. The results showed that the newly prepared peptides could be used effectively as a bio-recognition system and suggest that the glycoreplica peptides can be widely applied to therapeutic fields. Using the second technology, we could establish a functional lipidomics with a thin-layer chromatography-blot/matrix-assisted laser desorption ionization-time of flight mass spectrometry (TLC-Blot/MALDI-TOF MS) system. By transferring glycosphingolipids on a plastic membrane surface from a TLC plate, innovative biochemical approaches such as simple purification of individual glycosphingolipids, binding studies, and enzyme reactions could be developed. The combinations of these biochemical approaches and MALDI-TOF MS on the plastic membrane could provide new strategies for glycosphingolipid science and the field of lipidomics. In this review, typical applications of these two transfer technologies are introduced.
\end{abstract}

Keywords: glycosphingolipid, gangliosides, TLC-Blot/MALDI-TOF MS, phage-displayed peptide library, glycolipidomics, molecular mimicry

\section{Introduction}

Glycosphingolipids are essential membrane lipid components, together with phospholipids and cholesterol, and they have been characterized as molecules

*1 Tokushima Institute, Otsuka Pharmaceutical Co., Ltd., Tokushima, Japan.

$\dagger$ Correspondence should be addressed: T. Taki, 463-10 Kagasuno, Kawauchi-cho, Tokushima, Tokushima Institute, Otsuka Pharmaceutical Co., Ltd., 771-0192, Japan (e-mail: Taki.Takao@otsuka.jp).

Abbreviations: TLC: thin-layer chromatography; HPTLC plate: high performance thin-layer chromatography plate; MALDITOF MS: matrix assisted laser desorption ionization time of flight mass spectrometry; PVDF: polyvinylidene difluoride; MAb: monoclonal antibody; HPLC: high performance liquid chromatography; HSE cell: hepatic sinusoidal endothelial cell; GBS: GuillainBarré syndrome. involved in the cellular recognition, cell growth control, and differentiation-dependent expression, stage-specific antigens and tumor-associated antigens. ${ }^{1-5)}$ Much attention has been focused on aberrant glycosphingolipid expression and its relation to tumorigenic transformation. ${ }^{1)-3)}$ We also found unique glycosphingolipids and biosynthetic pathways in animals bearing tumors and human tumor sources. ${ }^{6)-14)}$ Through these studies, we demonstrated that some of these aberrant glycosphingolipids and metabolisms in tumor tissues were a kind of acquired mimetic glycosphingolipid expression arising during the tumorigenic process, which could be found in components of the intrinsic immune systems of host animals, such as macrophages and lymphocytes, to escape from the immune-surveillance system. ${ }^{7), 15)-17)}$ In glycosphingolipid studies per- 
a, Transfer technology 1

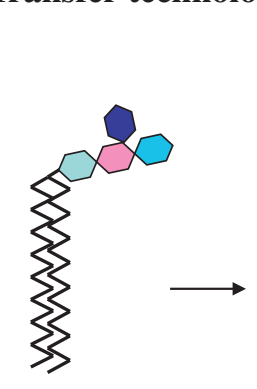

Glycosphingolipid
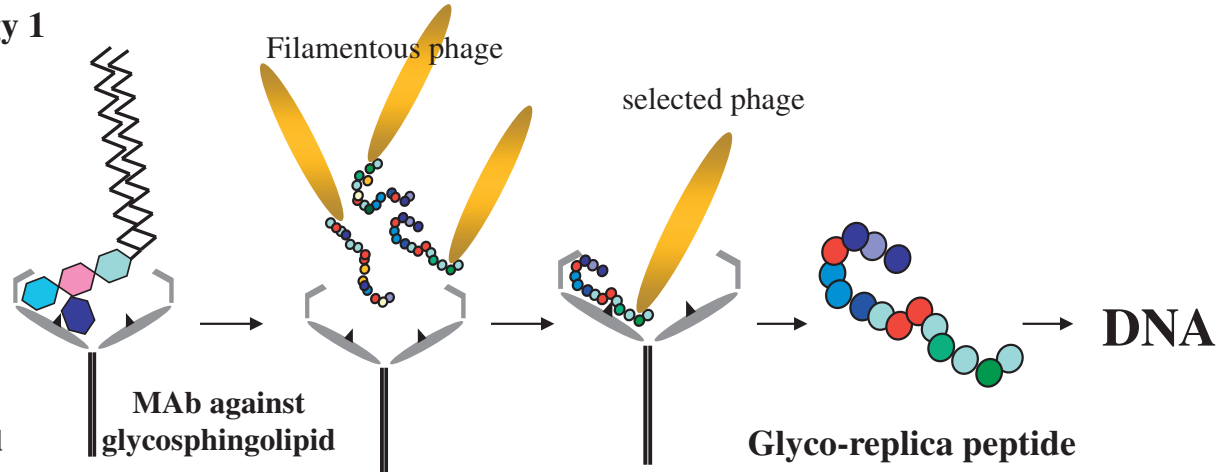

Glyco-replica peptide

\section{b, Transfer technology 2}

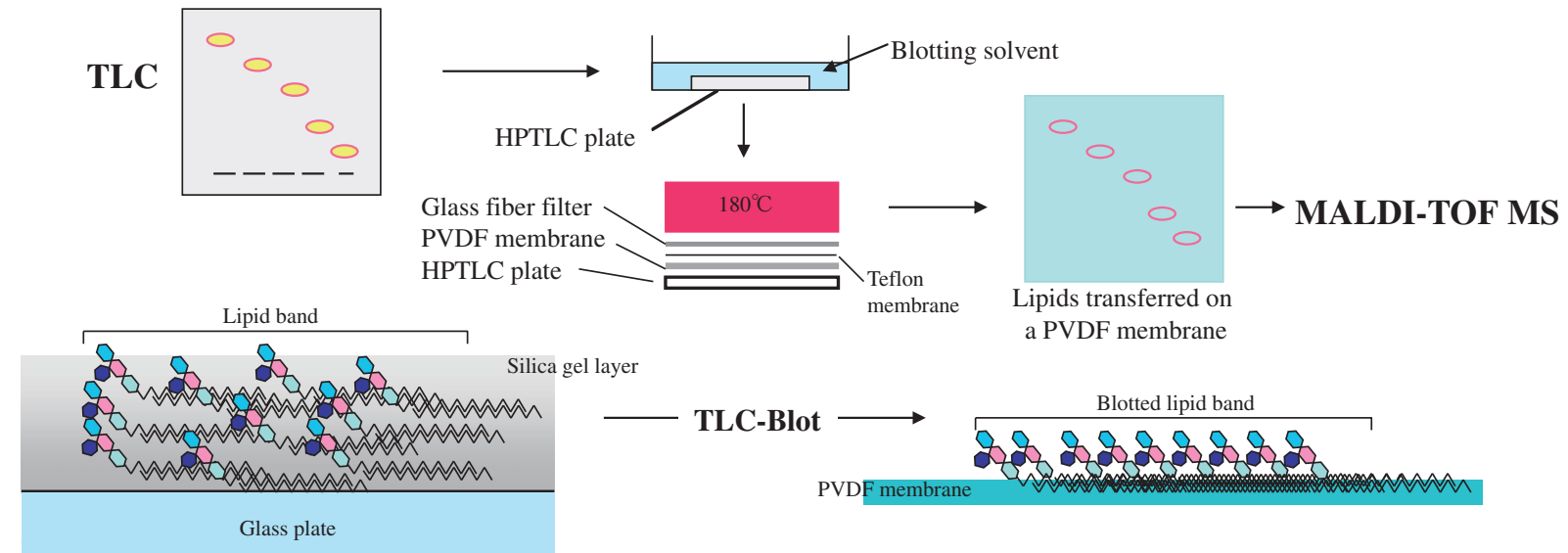

Fig. 1. The two types of transfer technology used in the present paper. a, Transfer technology 1. Transfer of glycosphingolipid to glycoreplica peptides by a phage-displayed peptide library. This is a reverse transcription from a glycosphingolipid to a DNA sequence through a glyco-replica peptide. b, Transfer technology 2. Transfer of glycosphingolipid from an HPTLC plate to a PVDF membrane by the TLC-Blot. Glycosphingolipids separated in silica gel are transferred to the surface of the PVDF membrane by the TLC-Blot, which can concentrate glycosphingolipids and provide easy access for enzymes, ligands and MS analysis (cited from ref. 27 and modified).

formed in the 1980s, much attention was focused on tumor-associated antigens and monoclonal antibody $(\mathrm{MAb})$ productions and their potential therapeutic application. ${ }^{18)-20)}$ In the 1990s, a molecular biotechnology was introduced to search for metabolizing enzymes and to produce glyco-gene-knockout animals to clarify the functions of glycosphingolipids, and these efforts quickly merged to form a new field of glycosphingolipid research. ${ }^{21)-23)}$

I looked for a different approach for characterizing this mysterious biomolecule, glycosphingolipid. In 1997, I came across a technology that used a phage-displayed peptide library to search for peptide ligands. ${ }^{24), 25)}$ This technology gave me the idea of using MAbs to prepare peptides that mimic the epitope structure of antigen glycosphingolipids. This would essentially replace the glycosphingolipids with peptides. We began to investigate the feasibility of this method and to examine the biological significance, in terms of bio-recognition, of the obtained glycosphingolipid mimetic peptides (Fig. 1a). ${ }^{26)}$

Another approach is to transfer lipids separated on an high performance thin-layer chromatography plate (HPTLC plate) to a PVDF membrane. This method takes advantages of well established TLC protocols. While immunological detection can be done on the HPTLC plate, unfortunately, the silica gel frequently slides from the glass plate during the treatment with antibody and the washing process. We therefore tried to develop a method for transferring lipids from the HPTLC plate to a plastic membrane to solve this problem. In 1994, we 
developed such a transfer method ${ }^{27)}$ and named it TLC-Blot. This method was found to be an innovative technology in lipid biochemistry because many enzyme reactions and chemical treatments could be performed on the PVDF membrane and the resulting reaction products could be analyzed by immunological reaction and also used for MS analysis. In addition, this technology led to new lipidomics approach by using improved mass spectrometer, ion trap-type MALDI-TOF MS system. The second part of this review concerns the development of TLC-Blot technologies and the road to functional lipidomics (Fig. 1b).

\section{Phage-displayed peptide library}

Figure 1a (Transfer technology 1) shows the principle of the phage-displayed peptide library. We used a randomly arranged, 15-mer peptide library displayed on the envelope protein PIII of filamentous phages. $^{25)}$ The library size was approximately $2.5 \times$ $10^{8}$ peptides. By incubation of the phage clones with a monoclonal antibody, phage clones having an affinity to the antigen-binding site were selected. The peptide sequences expressed on the PIII protein of the selected phage clones were determined by DNA sequencing analysis. The peptides obtained by this technology were examined whether they have functional activities similar to those of the antigen glycosphingolipids. When the biological significance of the obtained peptides was confirmed, we named them glycosphingolipid-replica peptides.

1-1. Glycosphingolipid-replica peptides and functional activities. First, we used the antiparagloboside mouse MAb H11 and the anti-lactotetraosylceramide mouse MAb AD $117 \mathrm{~m}$ for this approach. ${ }^{26)}$ These two glycosphingolipids are isomers of inner linkages of the lactotetraose moiety, but their terminal $\beta$-galactoses are the same linkage. We examined the degree of similarity among the obtained peptides by using these two different MAbs. Two phage clones, AD-1(RNVPPTFNDVYWIAF) and -2(VPPCFTLMYCAGVVR), were obtained with AD117m, and three phage clones, H111(FRSFHYHTGRWHWLR), -2(RNVPPIFNDVYWIAF) and -3(ARFPKELRGSVRSAH), with H11. Interestingly, we could obtain a common amino acid sequence, VPPXFXXXY, in the 9-mer peptide of AD-1, AD-2 and H11-2. The sequence of AD-1 peptide is almost same as that of H11-2. Only one amino acid, isoleucine is replaced with tyrosine in H11-2. But other two peptides H11-1 and H11-3 are completely different from AD-1 and AD-2. These 9- mer peptides showed a similar binding property for both the AD117m and H-11 MAbs, and also for a $\beta$-galactose-recognizing lectin ( $R$. communis lectin). This binding property changed substantially by altering the $\mathrm{X}$ with other amino acids. The 9-mer peptides (VPPXFTLMY) suppressed the Jack bean $\beta$-galactosidase activity to paragloboside, but interestingly, one 15-mer peptide, H11-3 of which amino acid sequence is completely different from others, activated the $\beta$-galactosidase activity to paragloboside. $^{26)}$ The results demonstrated that the molecular shapes obtained by this technology showed an agonistic and/or an antagonistic property to the glycosphingolipid counterparts. Since jack bean $\beta$ galactosidase is a heterodimeric enzyme, the result suggested that H11-3 peptide might interact with activation site of the enzyme without inhibiting access of substrate paragloboside into catalytic center.

Based on this first study, we tried to prepare ganglioside-replica peptides to confirm the biological functions obtained by this technology.

1-2. GD1 $\alpha$-replica peptides with antimetastatic activity. From the comparative study of glycosphingolipids of lymphosarcoma cell lines with different metastatic potentials, we found that GD1 $\alpha$ was a characteristic ganglioside of a sub-cell line (RAW117 H10) with high frequency of metastasis to the liver. The GD1 $\alpha$ was not found in the parental non-metastatic tumor cell line RAW117. ${ }^{28)}$ In earlier studies, we found GD $1 \alpha$ in the rat ascites hepatoma cell line AH 7974F, which has high malignant potential with an active invasive property, ${ }^{29)}$ and in a differentiation-resistant clone of mouse myeloid leukemia cells, M1-RI. ${ }^{30)}$ The functions of the GD1 $\alpha$ were examined and the ganglioside was found to be involved in the adhesion between RAW117 H10 and hepatic sinusoidal endothelial (HSE) cells based on the following results: 1, HSE cells specifically adhered to the area coated with the GD $1 \alpha$ on a plastic culture plate; 2 , The GD1 $\alpha$ strongly inhibited the adhesion of RAW117 H10 cells to HSE cells; 3, The MAb against GD1 $\alpha$ suppressed the adhesion of tumor cells to HSE cells. ${ }^{28)}$

We were interested in examining whether we could obtain peptides having biological activities similar to the GD1 $\alpha$ by biopanning with the phage peptide library and anti-GD1 $\alpha$ MAb. ${ }^{31)}$ Four phage clones were selected and two peptides, one (Q1P) (FRSDVRFWHWSTPFM) and the other (Q3P) (WHWRHRIPLQLAAGR), showed a common WHW motif. Then, we examined whether they 
exhibited an ability to suppress the adhesion between RAW117 H10 cells and HSE cells. The two 15-mer peptides showed not only inhibitory activity in terms of the adhesion but also in terms of the onset of metastasis of the RAW117 H10 cells to the liver of mice. One shot of $200 \mu \mathrm{g}$ Q3P per mouse suppressed the tumor metastasis to the lung by $100 \%$ and to the liver by $48.8 \%$. $^{31)}$

Based on this result, we determined the minimum sequence of the GD1 $\alpha$-replica peptide responsible for the biological function. ${ }^{32)}$ As shown in Fig. 2, the WHW sequence is necessary and sufficient to maintain the function. However, since the peptide linkage is quite flexible, we introduced a long alkyl chain to WHW (WHW-lipopeptides) to stabilize the molecular shape (Fig. 2c), thus making possible the formation of a liposomal structure to produce multivalence of the GD1 $\alpha$-replica peptide. The WHWlipopeptide is much more effective than the WHW peptide for inhibiting the adhesion between RAW117 H10 and HSE cells. Then, the WHW-peptide was applied to in vivo experiments. As shown in Table 1, the WHW-lipopeptide showed significant inhibitory activity in the metastasis of the lymphosarcoma RAW117 H10 cells to the liver. ${ }^{32)}$ The binding of WHW-lipopeptide to endothelial cells of the hepatic vasculature system seemed to block the binding site of RAW117 H10 cells, as already shown using GD1 $\alpha$ ganglioside. ${ }^{30)}$

1-3. The GD3-replica peptide and its immune response to produce anti-GD3 antibody. GD3 has been shown to be a characteristic ganglioside of melanoma, small cell lung carcinoma and neuroblastoma. ${ }^{33), 34)}$ GD3 has been selected as a target of metastatic melanoma by using anti-GD3 MAbs or GD3 mimetic vaccination. ${ }^{35)-37)}$ We tried to raise antibodies against GD3 ganglioside by immunizing GD3-replica peptides to examine whether the replica peptides truly mimic the shape of the ganglioside molecule. For this purpose, we used a MAb against GD3 (4F6). We obtained four peptides from the phage peptide library and selected one peptide, GD3P4 (RHAYRSMAEWGFLYS), with the highest binding activity to $4 \mathrm{~F} 6 .{ }^{38}$ ) The peptide was linked to $\varepsilon$-amino-groups of oligo-lysine to prepare multi-antigen peptide (MAP) and then used to immunize mice. The peptide MAP-GD3P4 induced antibodies against GD3, and the antiserum obtained by immunizing GD3 ganglioside showed high binding activity to GD3P4 peptides immobilized on a plastic plate. Finally, we could obtain one hybridoma producing anti-GD3 antibody (IgG3)
3D2, which showed binding to GD3 ganglioside. The MAb 3D2 showed high specificity to GD3 and the binding to human melanoma tissue was strong enough for immunohistochemical observation, and as strong as that of $4 \mathrm{~F} 6$ (Fig. 3a).

Next, we analyzed the DNA sequence of the hybridoma gene producing the 3D2 antibody. Surprisingly, the DNA sequence coding the immunoglobulin 3D2 was quite similar to that of the original 4 F6. We could detect only one amino acid substitution in the heavy chain CDR2 region $\mathrm{T}(4 \mathrm{~F} 6) \rightarrow$ $\mathrm{I}(3 \mathrm{D} 2)$. Even if there are some substitutions of nucleic acids, the substitutions do no affect the amino acid coding. In CDR regions of light chain, we found three amino acid substitutions as follows: $\mathrm{S}(4 \mathrm{~F} 6)$ to $\mathrm{T}(3 \mathrm{D} 2), \mathrm{A}(4 \mathrm{~F} 6)$ to $\mathrm{V}(3 \mathrm{D} 2)$ in CDR1 and $\mathrm{T}(4 \mathrm{~F} 6)$ to $\mathrm{S}(3 \mathrm{D} 2)$ in CDR3. However, these substituted amino acid properties were quite similar to those of the original one (Fig. 3b). The GD3P4 peptide is recognized by the immune system as having a ganglioside GD3 epitope structure and led to the production of an antibody quite similar to the original MAb 4F6, indicating that the molecular shape of the GD3P4 peptide is quite similar to that of GD3 ganglioside. ${ }^{38), 39)}$

1-4. Therapeutic use of GD3-replica peptides for lipo-oligosaccharide-induced experimental neuritis. Guillain-Barré syndrome (GBS) is characterized by muscle weakness in the arms and legs as well as the loss of deep tendon reflexes. In a previous study, we proposed a molecular mimetic mechanism to elicit GBS. ${ }^{40), 41)}$ In serum samples from GBS patients, antibody activity against GM1 ganglioside was frequently detected. And GM1 is a characteristic ganglioside in neural tissues. Many patients with GBS are found to be infected with the enteritis bacteria, Campylobacter jejuni. We found that the bacteria isolated from the patients contained a lipopolysaccharide bearing a GM1-like structure as a carbohydrate moiety. ${ }^{40), 41)}$ Actually, from a series of relationships between antibodies found in patients with GBS and $C$. jejuni strains, we found that $C$. jejuni strains had quite similar biosynthetic pathway of oligosaccharide of lipopolysaccharide to that of ganglioside in neuronal tissues. ${ }^{42-46)}$ Dr. Yu's laboratory demonstrated GD3 ganglioside mimicry in a model of GBS in Lewis rats by sensitization with GD3-like lipooligosaccharide from $C$. jejuni. ${ }^{47)}$ They tried to eliminate the pathogenic antibodies by using GD3-replica peptides previously reported by our group ${ }^{38)}$ and by another group of researchers. ${ }^{48)}$ It was found that one peptide, P(GD3)-4 (RHAYRSMAEWGFLYS), 


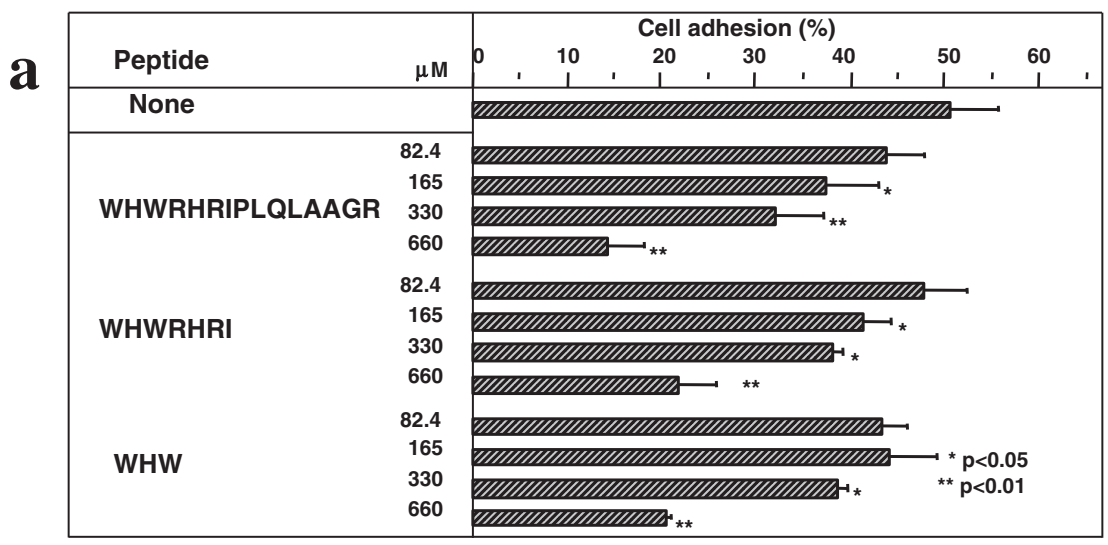

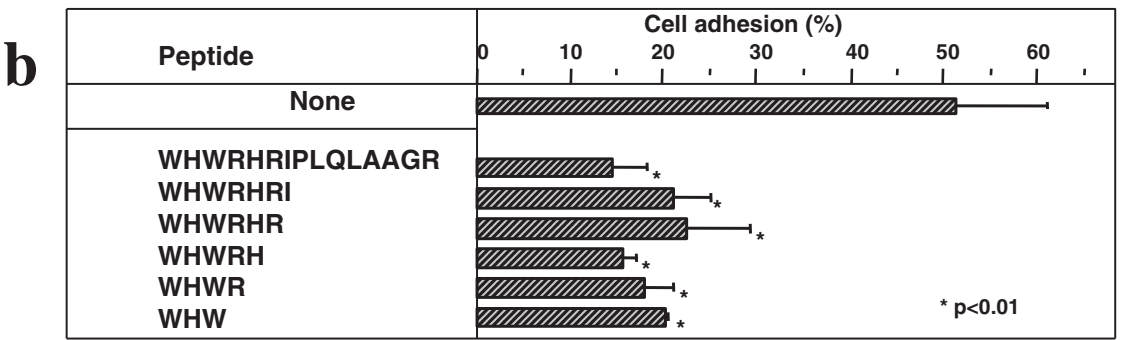

\begin{tabular}{|c|c|c|c|c|c|c|}
\hline \multirow{2}{*}{\multicolumn{3}{|c|}{$\begin{array}{l}\text { Peptide-modified liposomes } \\
\qquad \text { Peptide } \mu \mathrm{M}(\mathrm{DPPC} \mu \mathrm{M})\end{array}$}} & \multicolumn{3}{|c|}{ Cell Adhesion (\%) } & \multirow{2}{*}{$\begin{array}{r}40 \\
1 \\
\end{array}$} \\
\hline & & & 10 & 20 & 30 & \\
\hline \multicolumn{3}{|l|}{ None } & & & & \\
\hline Control liposomes & & $\begin{array}{r}(813) \\
(1625) \\
(3250)\end{array}$ & & & & \\
\hline WHW-liposomes & $\begin{array}{l}81.3 \\
163 \\
325\end{array}$ & $\begin{array}{r}(813) \\
(1625) \\
(3250)\end{array}$ & & & & \\
\hline
\end{tabular}

Fig. 2. Identification of the minimal sequence of GD1 $\alpha$-replica peptide required for the inhibition of cell adhesion of RAW117-H10 cells to HSE cells. a, The indicated concentrations of peptides were used for the inhibition study. b, Various peptides were used at concentration of $660 \mathrm{\mu M}$. c, Stearic acid was introduced to the amino terminal of each oligo-peptide to prepare the indicated lipopeptide (DPPC : cholesterol : peptide $=10: 5: 1$ ). The lipo-peptides were used at the indicated concentrations of peptides in liposomes $(\mathrm{\mu M})$ for the inhibitory assay. Control liposomes were prepared without peptides. The concentrations of liposomes expressed as DPPC concentrations $(\mu \mathrm{M})$ are given in parentheses (cited from ref. 32).

Table 1. Suppression of metastasis of RAW117-H10 cells in the liver by liposomal GD1 $\alpha$-replica peptide

\begin{tabular}{lccc}
\hline Group & $\begin{array}{c}\text { Liver weight } \\
(\mathrm{g} \pm \text { S.D. })\end{array}$ & $\begin{array}{c}\text { Increase in liver weight } \\
(\mathrm{g} \pm \text { S.D. })\end{array}$ & $\begin{array}{c}\text { Inhibition } \\
(\%)\end{array}$ \\
\hline Sham $^{\mathrm{a}}$ & $0.861 \pm 0.014$ & - & - \\
RAW117-H10 cells & $1.363 \pm 0.195$ & $0.502 \pm 0.195$ & 0 \\
RAW117-H10 cells + control liposomes & $1.305 \pm 0.110$ & $0.444 \pm 0.110$ & 11.6 \\
RAW117-H10 cells + WHW-liposomes & $1.137 \pm 0.040$ & $0.276 \pm 0.040$ & 45.0 \\
\hline
\end{tabular}

RAW117-H10 cells $\left(1 \times 10^{5} 0.2 \mathrm{ml} /\right.$ mouse) were injected in to mice (Balb/c female mice, $\left.\mathrm{n}=5\right)$ via the portal vein with or without liposomes (1.25 $\mathrm{mM}$ as a peptide). After 7 days, liver weight was measured for evaluating experimental metastasis. Compositions of liposomes were $\mathrm{DSPC}^{\mathrm{b}}:$ cholesterol $=2: 1$ for control liposomes and DSPC : cholesterol : peptide $=4: 2: 1$ for WHW peptide-modified liposomes.

${ }^{\mathrm{a}} 0.2 \mathrm{ml}$ of medium alone was injected into mice as a control.

bdistearoylphosphatidylcholine 
a

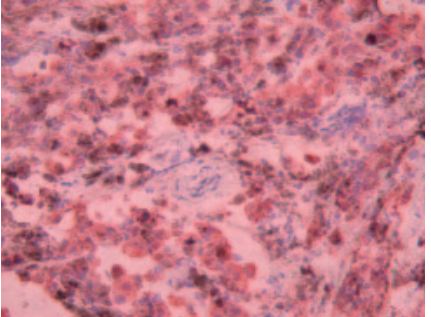

4F6

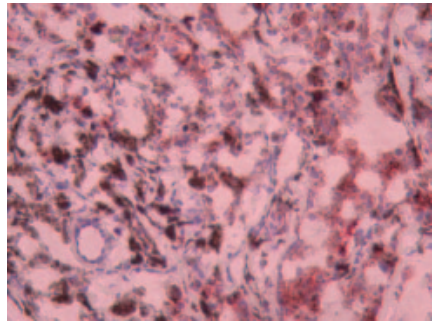

3D2

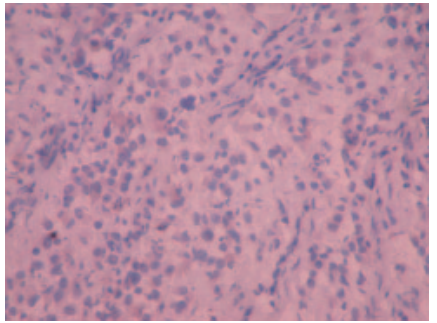

KM48 (control)

b-1

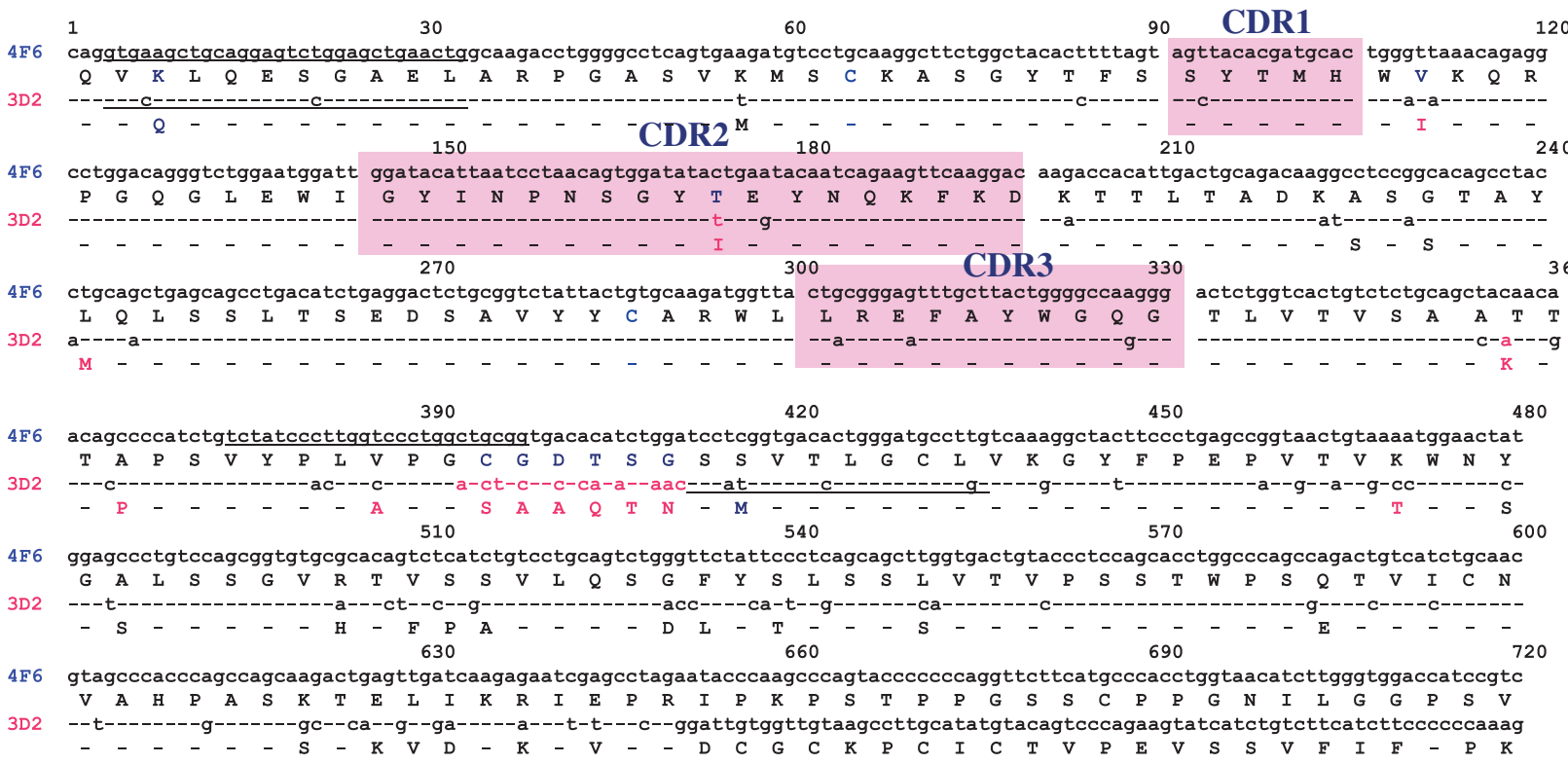

b-2

1

30

\section{CDR1}

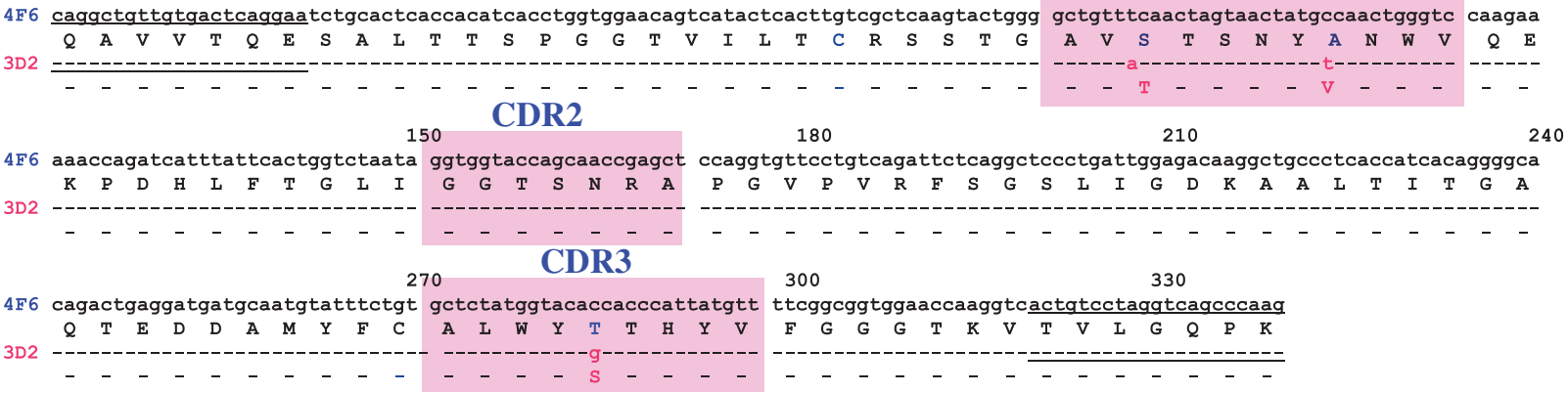

Fig. 3. a, Immunohistochemistry of human melanoma tissue with monoclonal antibodies. Staining with 4F6, 3D2 and KM48 as a monoclonal antibody, respectively. b, Comparison of the sequences of heavy chains (b-1) and light chains (b-2) between 4F6 and 3D2 (cited from ref. 38)

which corresponded to our GD3-replica peptide, GD3P4, induced in treated rats a remarkable restoration of motor nerve functions, as evidenced by improved histopathology, rotarod performance, and motor nerve conduction velocity. The GD3-replica effectively decreased the titer of anti-GD3/anti-LOS (GD3) antibodies and ameliorated peripheral nerve dysfunction in the sera of treated rats. Based on these findings, it was considered that peptide glycomimics of gangliosides may serve as powerful reagents for 
therapeutic intervention in GBS by neutralizing specific pathogenic anti-ganglioside antibodies. ${ }^{49)}$ The paper strongly supported our strategy and therapeutic application for GBS model rats by eliminating the ganglioside auto-antibody.

We thus succeeded in our goal of preparing functional and shape-mimetic peptides similar to that of the target glycosphingolipids by using the transfer technology of molecular replication (Fig. 1a). The obtained peptide sequences can be easily backtransferred to DNA sequences. Therefore, the results demonstrated a reverse transcription of gene expression, that is, from glycosphingolipid to peptide and to DNA. It is possible to prepare large scale glycoreplica peptides that could be substituted for the difficult technology of organic synthesis for glycosphingolipids.

\section{Transfer of glycosphingolipids from a TLC plate to a plastic membrane}

The most mysterious part in the investigation of lipids concerns the numerous variations of molecular species and their combinations in cell membranes. In our second approach, we developed a method for the transfer of lipids from an HPTLC plate to a plastic membrane. ${ }^{27)}$ Figure $1 \mathrm{~b}$ shows the principle of the TLC-Blot. Briefly, lipids separated on an HPTLC plate are made visible under UV light at $315 \mathrm{~nm}$ by primuline reagent, marked with a soft red pencil and dipped in a solvent mixture of isopropanol:0.2\% $\mathrm{CaCl}_{2}$ : methanol $(40: 20: 7, \mathrm{v} / \mathrm{v} / \mathrm{v})$ for 10 seconds. After removing the plate from the solvent mixture, the plate is mounted together with a polyvinylidene difluoride (PVDF) membrane, a teflon sheet and glass fiber sheet. This assembly is pressed for 30 seconds using a hot plate heated at $180^{\circ} \mathrm{C}$. By this procedure, most of the glycosphingolipids, including those that contain the phospholipids and the neutral lipids, can be transferred to the PVDF membrane. ${ }^{27)}$

The PVDF membrane is selected as the most desirable membrane because it is suitable for hydrophobic-hydrophobic interactions with lipids. Another advantage of this membrane is that it is stable against heat and acid treatment. For the TLC-Blot, less than $5 \mu \mathrm{g}$ of each lipid is recommended, because even if large amounts of lipids are applied to TLC, only a limited amount can be maintained on the PVDF membrane.

Interestingly, the transferred lipids are located on the opposite surface of the PVDF membrane to the HPTLC plate. It is clear that the red pencil markers are recognized on the same side of the membrane with lipids. Another evidence is that immunological detection of antigen glycosphingolipid with monoclonal antibody showed very clear staining on the one side only indicating that transferred lipids are concentrated on the surface of one side of the PVDF membrane. This means that immunological detection on the blotted PVDF membrane is much more sensitive than staining on the HPTLC plate. ${ }^{27)}$ Furthermore, the hydrophilic moieties of the transferred lipid face the outer environment. This is another point of this transfer, that is, "from lipids in silica gel to lipids on surface" (Fig. 1b). It should be noted that Towbin et al. reported the TLCblotting procedure before our own development of this method. ${ }^{50)}$ They used a nitrocellulose membrane, and the transfer was done by pressing the membrane onto a TLC plate that was wet by spraying with a solvent mixture of isopropanol: water $(2: 1, \mathrm{v} / \mathrm{v})$. Although the procedure was not always reproducible and did not always achieve the transfer of lipids, this report provided important clues that helped us to improve the lipid transfer procedure system.

2-1. Simple purification of glycosphingolipids and phospholipids. ${ }^{51)}$ The greatest challenge in glycosphingolipid biochemistry is the one step purification of individual lipid components from limited amount of samples. Silica gel column chromatography is the only tool available to purify the individual lipid species from total lipid extracts by elution with different solvent mixtures of chloroform, methanol and water. However, it is extremely difficult to obtain the lipid components as a homogenous band even if the column conditions and elution system are well controlled. We examined whether it would be possible to elute the lipid bands transferred on the membrane. Meconium is a good source of glycosphingolipids and also of carcinoembryonic materials, because it is a sloughing product from intestinal tissue in the fetal period. We could detect twenty bands in a neutral glycosphingolipid fraction by twodimensional TLC. The individual lipid bands transferred by the TLC-Blot were eluted with a small amount of a mixture of chloroform: methanol $(1: 1$, $\mathrm{v} / \mathrm{v}$ ), and checked by TLC. ${ }^{51)}$ The twenty individual extracts showed single bands by TLC (Fig. 4). This was a tremendous improvement in the purification of glycosphingolipids. This simple purification procedure can be applied to gangliosides and phospholipids and the results are very satisfactory. ${ }^{51)}$ The purified lipid components were considered to be intact based on the following observations: 1 . The extracted lipid showed the same mobility as that of the lipid before 
$\mathbf{a}$
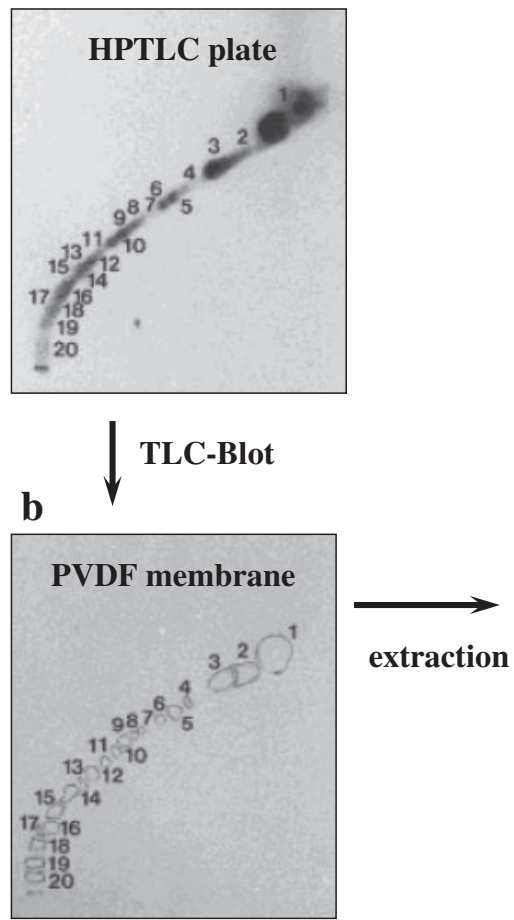

c

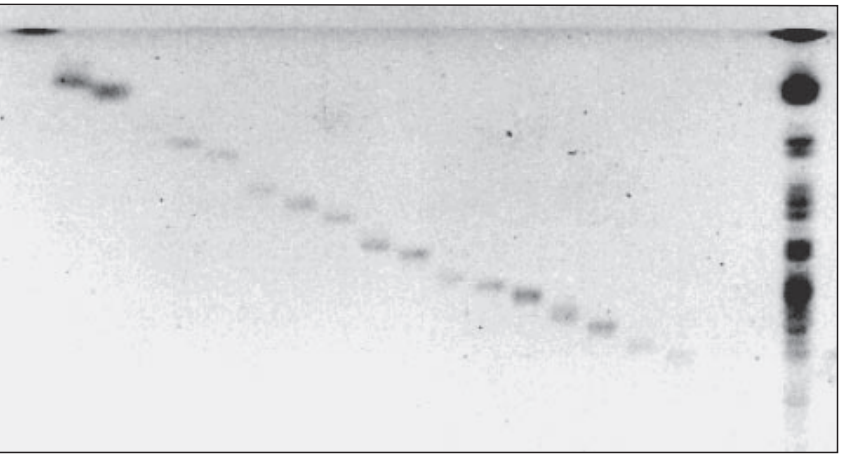

$\begin{array}{lllllllllllllllllllll}1 & 2 & 3 & 4 & 5 & 6 & 7 & 8 & 9 & 10 & 11 & 12 & 13 & 14 & 15 & 16 & 17 & 18 & 19 & 20 & \mathrm{t}\end{array}$

Orcinol reagent detection

Fig. 4. One step purification of individual glycosphingolipids of human meconium by TLC-Blot. a, Two-dimensional TLC of a human meconium neutral glycosphingolipid fraction. b, Marked lipid bands transferred from the HPTLC plate to the PVDF membrane by the TLC-Blot. c, Individual glycosphingolipid bands were extracted with chloroform: methanol (1:1, v/v) and applied to TLC. Orcinol reagent was used for the visualization (cited from ref. 51).

TLC-Blot; 2. MS analysis showed the same profile before and after TLC-Blot; 3. The immunological reactivity did not change after the TLC-Blot.

2-2. Binding studies employing lipids transferred to the PVDF membrane. The lipids transferred to the PVDF membrane from the HPTLC plate seemed to be useful for the binding study of micro-organisms, and for the detection of enzymes involved in lipid metabolism. Infections caused by pathogenic E. coli are often initiated by their adherence to the host cell surface via specific adhesions associated with fimbriae. E. coli expresses many types of fimbrial adhesins responsible for hemagglutination, which can be divided into different groups by their affinity to specific receptors. ${ }^{52), 53)}$ N-Glycolylneuraminic acid-containing glycosphingolipids were reported to be the ligands in E. coli K99. ${ }^{54), 55)}$ Gangliosides from the piglet intestine from which E. coli K99 was isolated, and bovine erythrocyte gangliosides were developed on an HPTLC plate and transferred to a PVDF membrane. ${ }^{56)}$ Then the binding of ${ }^{35} \mathrm{~S}$-labeled $E$. coli was performed on the PVDF membrane. Subsequently, a radioactive band corresponding to the band detected with autoradiography was subjected to MS analysis. The MS spectrum showed that the band detected in piglet intestine corresponded predominantly to N-glycolylneuraminic acid containing-GM3 with ceramide d18:1/C16h:0. And the band detected in bovine erythrocytes was identified as N-glycolylneuraminosyl paragloboside with ceramide composed of C24:0 or C22:0 fatty acid and d18:1 sphingosine. The MS analysis was thus quite powerful not only for discriminating between $\mathrm{N}$-acetylneuraminic acidand N-glycolylneuraminic acid-containing gangliosides but also for discriminating between molecular species of their ceramide moieties as the receptor molecules. ${ }^{56)}$

2-3. Detection of enzymes involved in glycosphingolipid metabolism. ${ }^{57)}$ The lipids immobilized on the PVDF membrane by the TLC-Blot seem to mimic the situation in the cell membrane, because, the ceramide or glyceride moiety is considered to be attached to the PVDF membrane by a hydrophobic interaction, and the hydrophilic moieties of phospholipids and glycosphingolipids are thought to be 
exposed to the outer environment (Fig. 1b). We tried to detect enzymes involved in the glycosphingolipid metabolism using a glycosphingolipid-transferred PVDF membrane, because the assay procedures for both glycosidases and glycosyltransferases are quite complicated. In the glycosidase assay, artificial fluorescence-labeled glycoside compounds were used. Since they are not natural compounds, the obtained enzyme activities do not specifically target individual glycosphingolipids. For glycosyltransferase assay, we had to use radioactive sugar nucleosides and the assay procedure contained many individual separation processes and was quite time consuming. As one example, we developed sialylneolactose-containing gangliosides, sialylparagloboside, i-ganglioside, Iganglioside and GM3 on an HPTLC plate, and performed the TLC-Blot. These gangliosides on the membrane were treated with sialidase from $C l$. perfringens. After incubation, glycosphingolipids having Gal $\beta 1-4 \mathrm{GlcNAc} \beta 1-3 \mathrm{Gal} \beta$ epitope exposed by the sialidase treatment were detected by immunostaining with MAb H11, which recognized the terminal epitope. The bands corresponding to sialylparagloboside, i-ganglioside and I-ganglioside could be visualized by immunostaining. The activity could be determined with a densitometer. Dose-dependent activity was demonstrated by this procedure. ${ }^{57)}$

For the assay of $\beta$-galactosyltransferase activity, various amounts of Lc3Cer (GlcNAc $\beta 1$-3Gal $\beta 1$ 4 GlcCer) were developed on an HPTLC plate and then transferred to a PVDF membrane by TLC-Blot. The Lc3Cer-bearing membrane was incubated with $\beta$-galactosyltransferase with UDP-Gal and cofactors. Incubation products were detected with MAb H11 and determined with a densitometer. This procedure is quite simple and does not require the use of radioactive sugar nucleotides, and the products can be clearly identified by using MAbs with high epitope specificity. ${ }^{57)}$

Another application was developed by using a substrate immobilized membrane. The principle behind this application was to transfer lipid-metabolizing enzymes separated on polyacrylamide electrophoresis (PAGE) to a substrate lipid-coated PVDF membrane to identify the localization of enzyme(s) by visualizing the incubation product with MAb. We could recognize localization of sialidase from $C l$. perfringens on the polyacrylamide gel by using sialylparagloboside as substrate and MAb H11 against paragloboside. ${ }^{57)}$ By this procedure, the sialidase can be easily purified and its amino acid sequence can be identified.
A similar approach was taken by using a [N-methyl- $\left.{ }^{14} \mathrm{C}\right]$-sphingomyeline-impregnated PVDF membrane. ${ }^{58)}$ A sphingomyelinase-containing crude enzyme from $\mathrm{Cl}$. perfringens was applied to native PAGE and the gel was mounted on the ${ }^{14} \mathrm{C}$ sphingomyeline-impregnated PVDF membrane. After incubating overnight at $37^{\circ} \mathrm{C}$, the PVDF membrane was subjected to autoradiography to visualize the enzyme band. The autoradiogram showed a white band on a black background that corresponded to the sphingomyelinase activity. ${ }^{58)}$

Bogdanov and colleagues demonstrated that phosphatidylethanolamine (PE) acts as a molecular chaperone in the folding of the polytopic membrane protein lactose permease of E. coli. ${ }^{59)}$ Various phospholipids were separated on an HPTLC plate and transferred to nitrocellulose membrane by the modified TLC-Blot. To the individual phospholipid position of the blotted membrane, lactose permease from PE-deficient (-PE) or PE-containing cells was transferred by Western blot. Then the nitrocellulose membrane was incubated and treated with a monoclonal antibody that recognizes a conformationally sensitive epitope of lactose permease ${ }^{60)}$ in order to search for a novel role of phospholipids in the assembly of a membrane protein. Interestingly, the permease from PE-deficient cells was recognized by this MAb only on the position of the PE band, indicating that $\mathrm{PE}$ plays a positive role in reconstitution of the structurally active membrane transport protein even on membranes made up of chemicals such as nitrocellulose.

2-4. MS analysis of glycosphingolipids transferred on a PVDF membrane by TLC-Blot. In 1995, we considered that it would be a great advantage of the TLC-Blot method if the clearly separated bands of lipids transferred onto a PVDF membrane by TLC-Blot could be analyzed directly by MS. Before this trial, the TLC-MS system was developed by Kushi and Handa. ${ }^{61)}$ However, the potential for silica gel contamination of the newly developed instrument was a major problem. We examined to analyze glycosphingolipids transferred on the PVDF membrane by secondary ion mass spectrometry (Finnigan TSQ 70) and named this new method TLC-Blot/SIMS. We found that it worked very well with high sensitivity. ${ }^{62)}$ Based on this result, we applied this method to the identification of glycosphingolipids in rat mammary tumor cell lines with different metastatic potentials (MTC, parental cell line; MTLn2, non-metastatic cell line; MTLn3, high metastatic potential to the lung). ${ }^{63)}$ 
We were able to analyze all glycosphingolipid bands (13 bands in MTLn2 and 17 bands in MTLn3) by using $1 \times 10^{7}$ cells. In the non-metastatic cell line MTLn2, a novel type of blood group A active glycosphingolipid was discovered. This result surprised us at that time, 1996, because most of the glycosphingolipids were identified by using very small amounts of samples. At the time, I urged MS makers to develop a new TLC-Blot/MS system for lipidomics research. Unfortunately, the time seemed ripe for proteomics but not for lipids. The development of such a system would have to wait for more than 10 years.

2-5. Identification of an auto-antigen in Meniere's disease. Meniere's disease is an inner ear disease characterized by episodic attacks of vertigo, fluctuating cochlear hearing loss, tinnitus, and a feeling of fullness in the affected ear. The condition underlying Meniere's disease is endolymphatic hydrops. The cause of endolymphatic hydrops remains unknown, but the autoimmune hypothesis has been proposed and actively discussed. ${ }^{64), 65)}$ This hypothesis is based on clinical findings of increases in blood immune complex levels ${ }^{66), 67)}$ the efficacy of steroids for hearing loss, ${ }^{65), 66), 68), 69)}$ and the high concentration of $\operatorname{IgG}$ in endolymph, ${ }^{70)}$ as well as the basic findings that endolymphatic hydrops are observed in animals immunized with inner ear tissues, ${ }^{71), 72)}$ resulting in fluctuating hearing loss. ${ }^{73)}$

Based on these findings, we tried to determine antigens that might be present in inner ear tissue. We had a chance to analyze human acoustic neurinoma samples and tried to detect antigens in the ganglioside fractions of these samples. ${ }^{74}$ Although the amounts of samples were quite limited, we detected a total of 7 ganglioside bands by TLC, and all the gangliosides were identified by the TLC-Blot/SIMS. They were five ganglio-series gangliosides, GM3, GM2, GM1a, GD3, and GD1a, and two neolactoseries gangliosides, sialylparagloboside and sialyl-i ganglioside. Sialyl-i was found to be a possible natural antigen based on the immune reactivity of serum samples from patients with Meniere's disease. Five of the 11 patients showed immune reactivity to sialyl-i ganglioside, indicating that this ganglioside may be an auto-antigen involved in the pathogenesis of Meniere's disease. ${ }^{74)}$

2-6. Approach to a new lipidomics using TLC-Blot/MALDI-TOF MS. After our study using TLC-Blot/SIMS, the mass spectrometer underwent rapid development, and the ion trap-type MALDI-TOF MS instrument was found to be quite useful for the analysis of lipids transferred to a PVDF membrane. Figure 5 shows the TLC-Blot/MALDITOF MS system used for a new approach in functional lipidomics; the illustration is modified from that in ref. 75. Despite the irregular surfaces of the ganglioside band on PVDF membranes, the ion trap helped to minimize the mass error between the predicted and the observed masses, and it was revealed that the mass accuracy was highly preserved. Furthermore, by this MS instrument, scanning MS became possible and the lipid band area transferred onto the membrane could be analyzed by raster scanning. We examined the quantitative detection and limit of this procedure using L- $\alpha$ dipalmitoylphosphatidylcholine (PC). When this phospholipid was applied to an HPTLC plate $5 \mathrm{~mm}$ in width, a band corresponding to 5 pmol was detectable with TLC-Blot/MALDI-TOF MS. A calibration curve was obtained according to these ion intensities, and the value of the determination efficient showed sufficient linearity $\left(\mathrm{R}^{2}=0.9896\right)$. This method makes it possible to detect minor components of lipids, and it can also be applied to differential analyses of various lipids due to its quantitative potential and ability to simultaneously assay for multiple lipid variances. ${ }^{76)}$ This imaging MS (IMS) analysis with raster scanning was applied to ganglioside analyses on the transfer membrane. ${ }^{77}$ )

Gangliosides are routinely analyzed in the negative ion mode in order to reduce the metastable fragmentation of sialic acid. Figure 6 shows an example of the analysis of GM1 ganglioside by the TLC-Blot/MALDI-TOF MS system. ${ }^{77)}$ Figure 6a shows the detection limit by primuline staining and MS analysis. The lower limit was 1 pmol by MS, even though the signal was quite low, but the band corresponding to $10 \mathrm{pmol}$ showed clear molecular ion signals at $m / z 1544$ and $m / z 1572$. In order to determine the molecular species of these two signals, $\mathrm{MS} / \mathrm{MS}$, and MS/MS/MS analysis was done using a band of $10 \mathrm{pmol}$ GM1. The MS/MS and MS/MS/MS analyses of these molecular species clearly indicated that they differed by two sphingosine bases (d18:1 and $\mathrm{d} 20: 1$ ) in the ceramide moiety but they had the same carbohydrate sequence. The scanning MS of $m / z 1544$ and 1572 was done to see the localization of these two molecular species in the GM1 ganglioside band. Figure $6 \mathrm{~b}((\mathrm{C}),(\mathrm{D}),(\mathrm{E}))$ shows the imaging mass spectrometry of GM1 by TLC-Blot/MALDITOF MS. Ion images of the GM1 band of different ceramide moieties, $m / z 1572$ and 1544, respectively, are shown. The GM1 molecular species with d20:1 


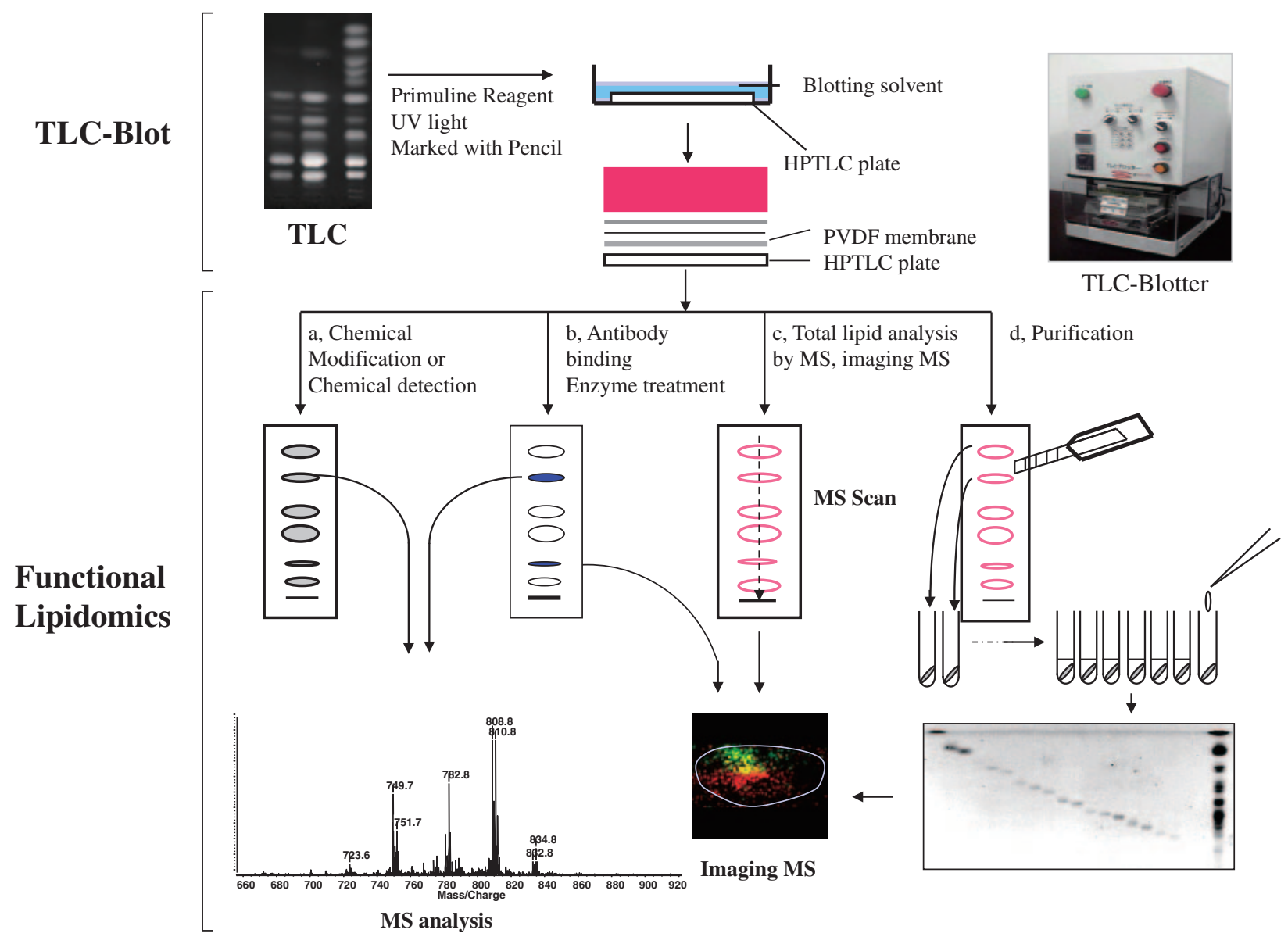

Fig. 5. Scheme of functional lipidomics by TLC-Blot/MALDI-TOF MS. Individual lipids transferred to a PVDF membrane from HPTLC plate by TLC-Blot were subjected to chemical modifications (a), enzyme treatments, binding studies (b), MS scanning of all lipid bands (c) and purification (d). The target bands obtained by these treatments could be used for MALDI-TOF MS analysis. Imaging MS was also applied to the PVDF membrane (cited from ref. 75 and modified).

sphingosine is located in the upper area and that of $\mathrm{d} 18: 1$ sphingosine is located in the lower part of the band.

2-7. Ganglioside molecular species in the hippocampus of patients with Alzheimer's

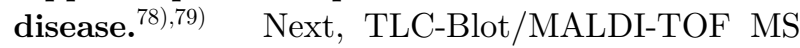
was applied to human brain samples obtained from the Netherlands Brain Bank (NBB). All samples were anonymous and were obtained under conditions of informed consent according to the ethical guidelines of the NBB. Altogether 20 bands, including cholesterol, phospholipid and glycosphingolipid bands, were clearly separated by two-dimensional TLC. Nineteen of the 20 bands were characterized by MALDI-TOF MS, and the remaining band was unknown. ${ }^{78)}$ During these MS analyses, we found a significant change in the molecular species of gangliosides in patients with Alzheimer's disease. Figure 7 shows a TLC profile of total lipids from the gray matter of the hippocampus region obtained from patients with Alzheimer's disease, Parkinson's disease and a control disease. ${ }^{79)}$ The TLC clearly showed a decrease in b-series gangliosides, GD1b and GT1b, in patients with Alzheimer's disease but not in those with Parkinson's disease. This was quite a characteristic observation in the hippocampus, and this kind of decrease was not observed in the inferior frontal gyrus used as control area.

Next, we examined the distribution of molecular species of individual gangliosides in the hippocampus areas. In this analysis, we had to be very careful, because the sialic acid of disialo- or trisialo-gangliosides is easily released to produce GM1 corresponding fragment during the ionization process of MS analysis. The accumulated results of the MS scanning of individual ganglioside bands are shown in Fig. 8a. A 
$\mathbf{a}$
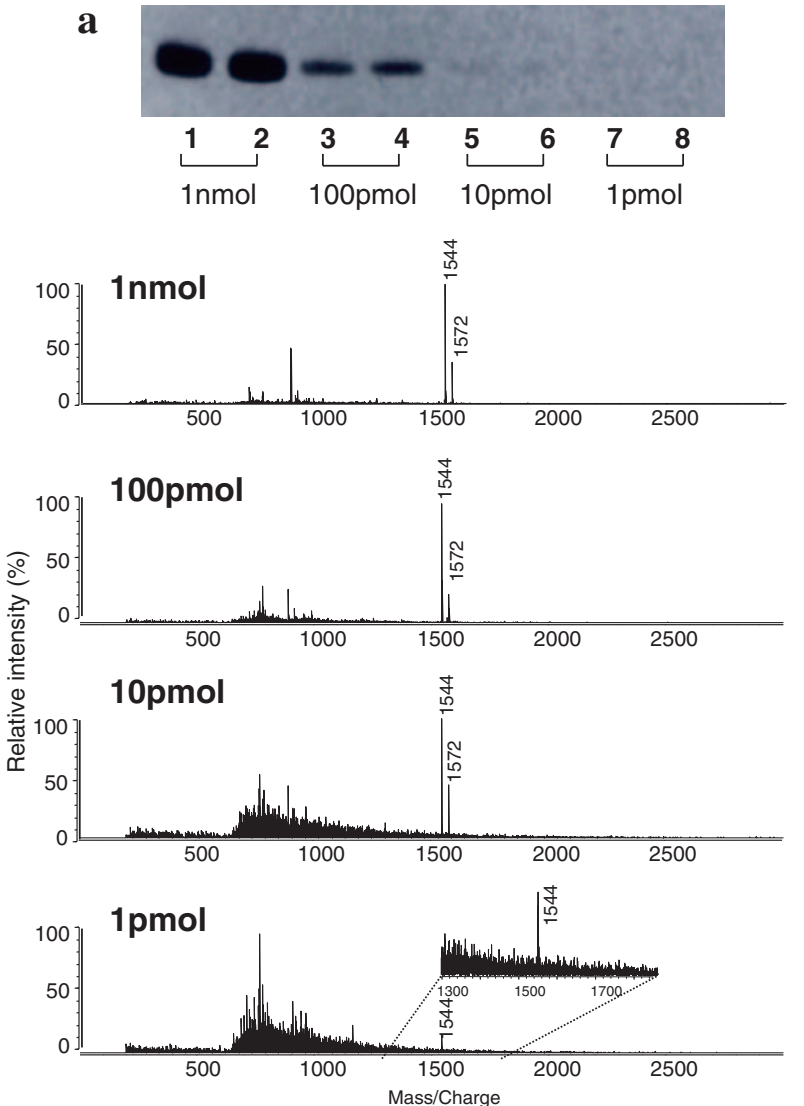

b

(B) Primuline

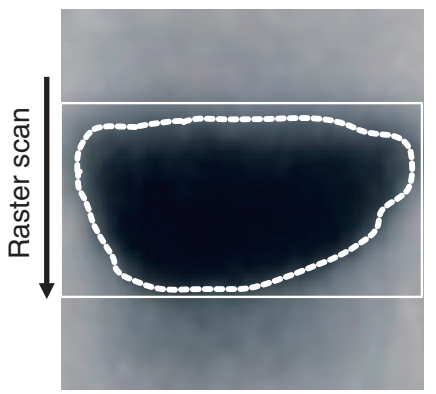

(D) IMS: $m / z 1544$ GM1(d18:1/C18:0)

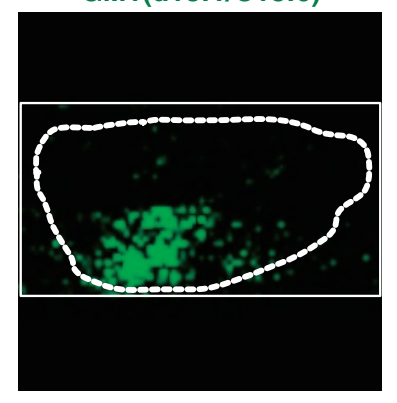

(C) IMS: $m / z 1572$ GM1(d20:1/C18:0)

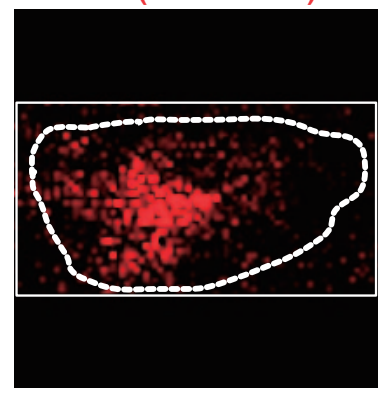

(E) merged

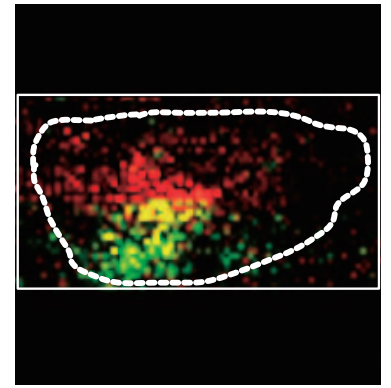

Fig. 6. TLC-Blot/MALDI-TOF MS and imaging MS by scanning of GM1 ganglioside band. a, The indicated amounts of GM1 were developed on an HPTLC plate and transferred to a PVDF membrane by the TLC-Blot. Each MS spectrum shows the GM1 band transferred on the PVDF membrane. The spectrum shows 2 major signals, $m / z 1544$ and 1572. b, Imaging MS of two GM1 molecular species on the transferred GM1 band on the PVDF membrane. GM1 with ceramide d20:1/C18:0 moved faster than GM1 with d18:1/ C18:0 on the HPTLC plate (cited from ref. 77 and modified).

signal corresponding to GM1 was detected as a main peak in each case. In the case of GM1, the signal strength of $m / z 1544$ was similar to that of $m / z 1572$ both in Parkinson's disease and control patients. But in the Alzheimer's patients, the signal of $\mathrm{m} / z 1544$ was higher than that of $m / z 1572$. This tendency was much clearer for the gangliosides GD1a, GD1b and GT1b. In the b-series gangliosides, GD1b and GT1b, d20:1 sphingosine-containing molecular species were predominant in control patients, even in Parkinson's disease patients, but d18:1-containing molecular species were stronger than $\mathrm{d} 20$ :1-containing ones in Alzheimer's disease patients. $\left.{ }^{79}\right)$ The distributions of the molecular species of these gangliosides on the blotted PVDF membrane are shown as MS imaging in Fig. 8b.

This was the first demonstration of a change in the molecular species of gangliosides in the hippocampus area of patients with Alzheimer's disease.
Many papers have reported that the level of $\mathrm{d} 20: 1$ sphingosine-containing gangliosides increases with age ${ }^{80-84)}$ From this point of view, Alzheimer's disease is a kind of metabolic disease of ganglioside molecules. The disease pathogenesis would thus involve two mechanisms, a reduction of the b-series ganglioside synthetic pathway and a change of the sphingosine metabolic process. ${ }^{85)}$ This change of gangliosides in the hippocampus area seemed to be involved in eliciting the disease, because a similar change of ganglioside molecular species was also found in the hippocampus area in an animal model of Alzheimer's disease, which was produced by transfection of gene of human double Swedish/London type mutation constructed amyloid precursor protein. ${ }^{86)}$

Recently, much attention has been focused on the development of molecular imaging MS. ${ }^{87-90)}$ This imaging MS technology has also been used for the detection of molecular species distributed on the 
a

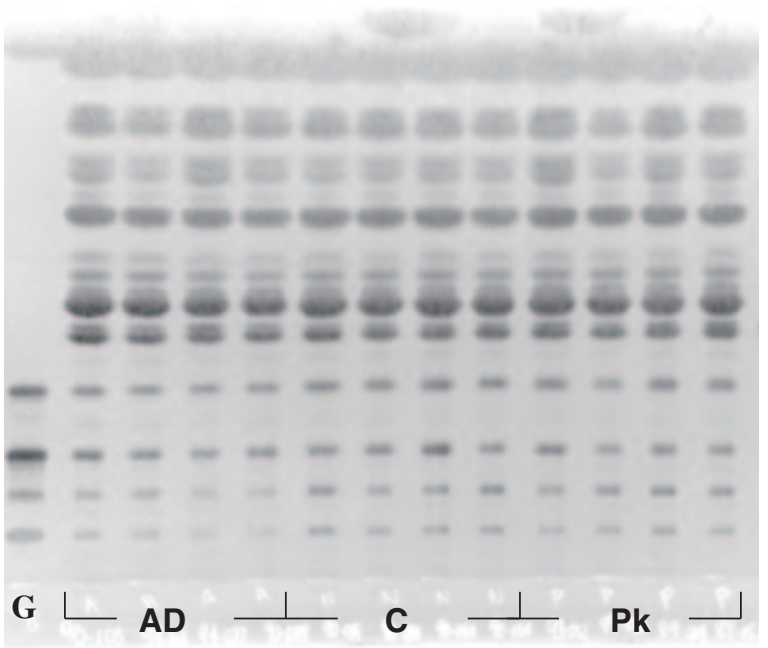

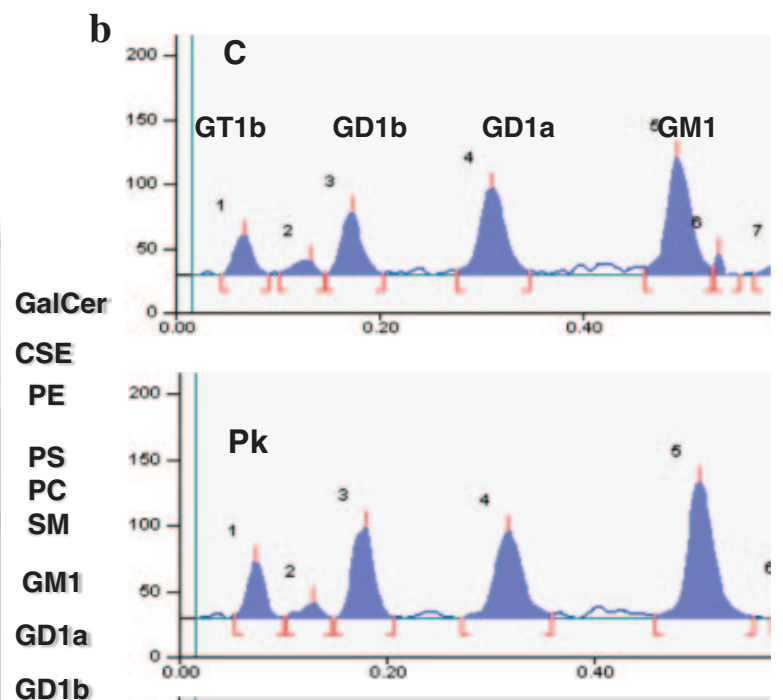

GT1b

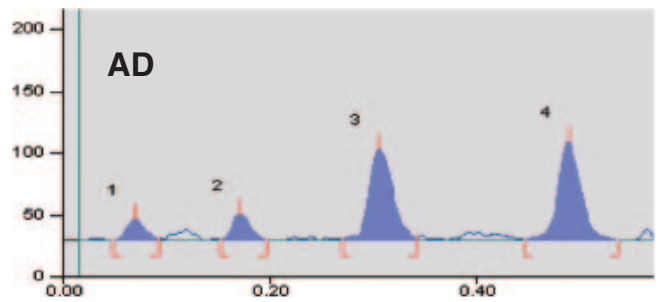

Fig. 7. TLC of total lipids from the hippocampus gray matter areas. a, Total lipids extracted from the hippocampus region of patients with Alzheimer's disease (AD), with Parkinson's disease (Pk) and a control disease were developed on an HPTLC plate. G, standard gangliosides. Lipid bands were made visible under UV at $315 \mathrm{~nm}$ by spraying with primuline reagent. b, Results of a typical densitometer analysis of gangliosides are shown in the right-side panel (cited from ref. 79).

lipid bands of the transferred membrane. ${ }^{76)-79)}$ By introducing the binding experiments or modifications with chemical reagents or enzymes on lipid bands on the membrane, ${ }^{75), 91)}$ we can easily determine the modified band(s) and confirm the resulting modifications with TLC-Blot/MALDI-TOF MS (Fig. 5).

\section{Conclusion}

The present review has focused on the two transfer technologies for glycosphingolipids. The first technology consists of reverse transcription from a glycosphingolipid to a DNA sequence through a glyco-replica peptide. The obtained results present a bio-recognition system as shape, which does not care if the target is glycoconjugate, peptide or protein. One typical example is anti-idiotype antibody production. To discriminate foreign molecules, living cells (immune cells) recognize the shape of the molecule and present it as self or non-self on the cell surfaces of antigen-presenting cells. And by applying this technology, new functional and therapeutic approaches employing glycosphingolipids could be introduced.
The second technology consists of a physicochemical transfer of glycosphingolipids from the silica gel layer to the surface of a plastic membrane. Glycosphingolipids spread in the silica gel layer could be concentrated on the PVDF membrane surface while exposing their carbohydrate moieties to the outer environment, resulting in ready access for various biological and physicochemical compounds. Taken together, these combinations of different types of access provide us with a new functional lipidomics.

\section{Acknowledgements}

I would like to express my great appreciation to Prof. Dr. Tamio Yamakawa for providing me the opportunity to submit this review and to Prof. Dr. Yoshitaka Nagai his encouragement throughout my research. I would also like to express my sincere thanks to Profs. Makoto Matsumoto, Tamotsu Taketomi and Shizuo Handa for their kind instruction and for providing me the chance to work in the field of lipid biochemistry. Finally, I would like to thank all my collaborators, whose efforts were indispensable to my research. 
a

(A) GM1 in Hippocampus Gray Matter

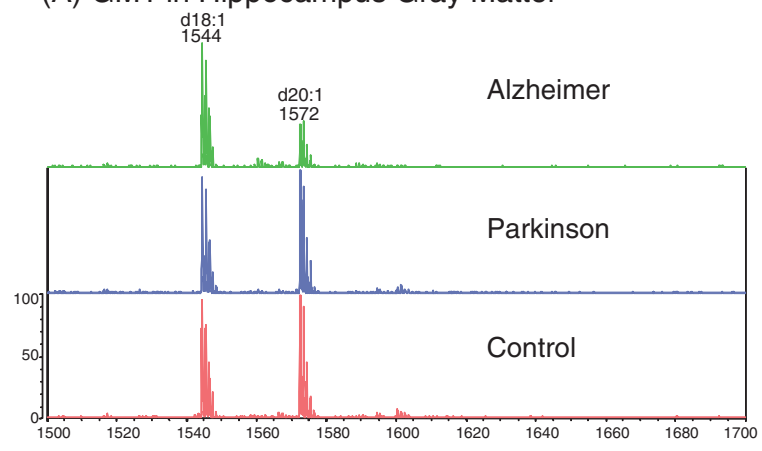

(C) GD1b in Hippocampus Gray Matter

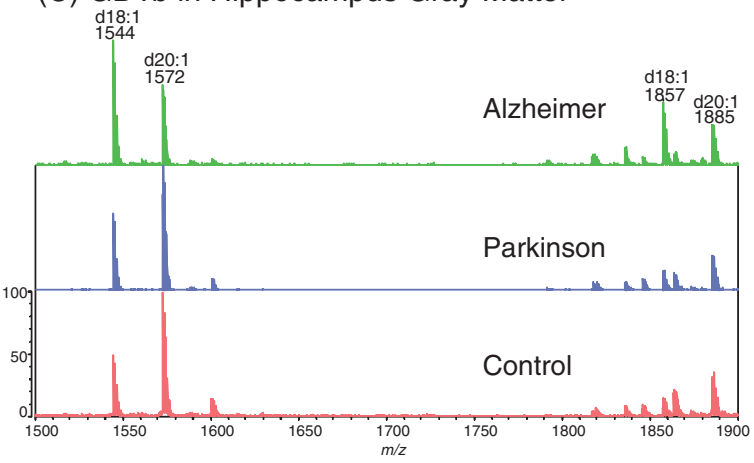

(B) GD1a in Hippocampus Gray Matter d18:1
1544

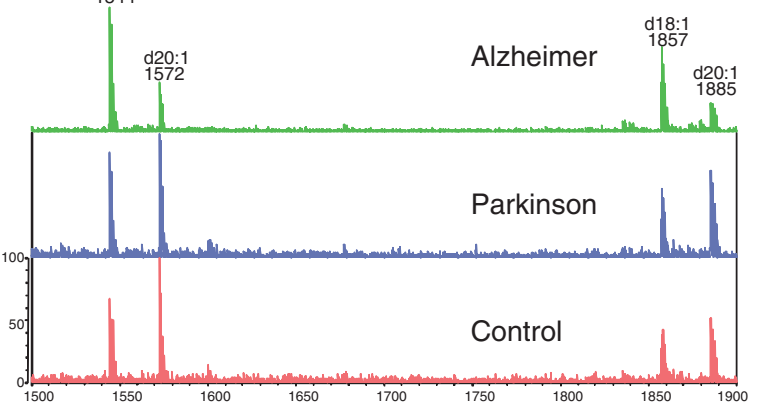

(D) GT1b in Hippocampus Gray Matter d18:1
1544 d20:

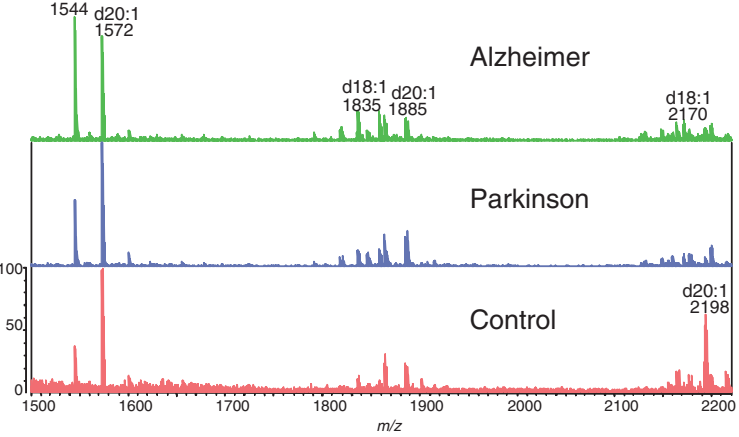

b

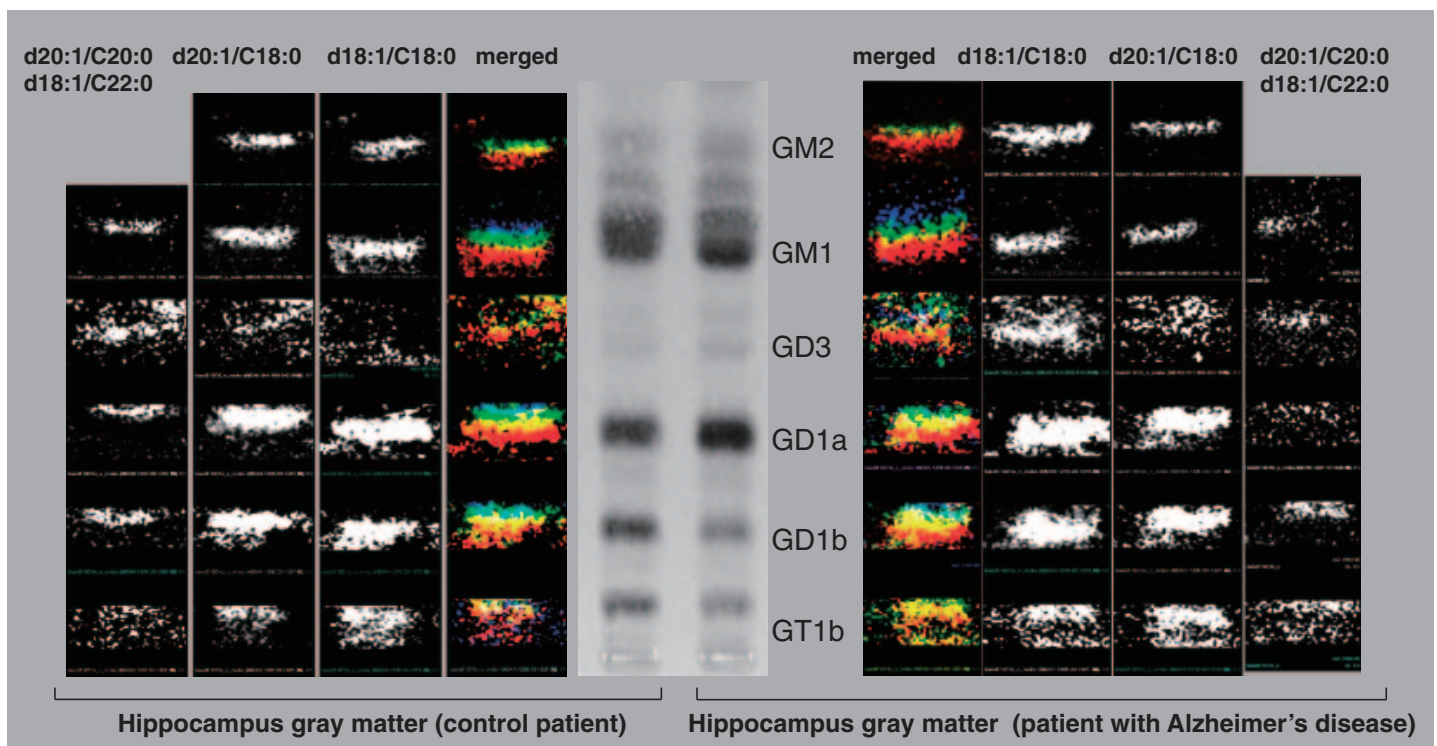

Fig. 8. TLC-Blot/MALDI-TOF MS and imaging MS of gangliosides. a, TLC-Blot/MALDI-TOF MS of gangliosides. The ganglioside bands obtained in Fig. 7 were transferred to the PVDF membrane by the TLC-Blot. The bands of GM1 (A), GD1a (B), GD1b (C) and GT1b (D) were analyzed by molecular scanning with MALDI-TOF MS (cited from ref. 79). b, Imaging MS of gangliosides. Gangliosides of the hippocampus gray matter from a control patient and a patient with Alzheimer's disease were separated on an HPTLC plate and transferred to the PVDF membrane by the TLC-Blot. Each band was employed for raster scanning, and the obtained signals corresponding to molecular species, d18:1/C18:0, d20:1/C18:0 and d20:1/C20:0 or d18:1/C22:0, are shown as MS imaging. And they are also presented as merged images of ganglioside molecular species with ceramide d18:1/C18:0 (red dot), d20:1/ C18:0 (green dot) and d20:1/C20:0 or d18:1/C22:0 (blue dot) (cited from ref. 79 and modified). 


\section{References}

1) Hakomori, S. (1981) Glycosphingolipids in cellular interaction, differentiation, and oncogenesis. Annu. Rev. Biochem. 50, 733-764.

2) Hakomori, S. (1985) Aberrant glycosylation in cancer cell membrane as focused on glycolipids: over view and perspective. Cancer Res. 45, 24052414.

3) Fredman, P. (1993) Glycosphingolipid tumor antigens. Adv. Lipid Res. 25, 213-234.

4) Yu, R.K., Macala, L.J., Taki, T., Weifeld, H.M. and Yu, F.S. (1988) Developmental changes in ganglioside composition and synthesis in embryonic rat brain. J. Neurochem. 50, 1825-1829.

5) Handa, K. and Hakomori, S. (2012) Carbohydrate to carbohydrate interaction in development process and cancer progression. Glycoconj. J. 29, 627-637.

6) Taki, T., Hirabayashi, Y., Suzuki, Y., Matsumoto, M. and Kojima, K. (1978) Comparative study of glycolipid composition of plasma membranes among two types of rat hepatoma and normal rat liver. J. Biochem. 83, 1517-1520.

7) Taki, T., Hirabayashi, Y., Kojima, K. and Matsumoto, M. (1979) Biosynthesis of different gangliosides in two types of rat ascites hepatoma cells with different degree of cell adhesiveness. Biochim. Biophys. Acta 572, 113-120.

8) Hirabayashi, Y., Taki, T. and Matsumoto, M. (1979) Tumor ganglioside -Natural occurrence of GM1b-. FEBS Lett. 100, 253-257.

9) Taki, T., Kojima, S., Seto, H., Yamada, H. and Matsumoto, M. (1984) Glycolipid composition of ascitic fluids from patients with cancer. J. Biochem. 96, 1257-1265.

10) Taki, T., Ishikawa, H., Imai, K., Yachi, A. and Matsumoto, M. (1985) Immunological analysis of glycolipids on cell surfaces of cultured human tumor cell lines.-Expression of lactoneotetraosylceramide on tumor cell surfaces-. J. Biochem. 98, 887-895.

11) Taki, T., Yamamoto, K., Ishii, K., Myoga, A., Sekiguchi, K., Ikeda, I., Kurata, K., Handa, S. and Matsumoto, M. (1990) Accumulation of gangliosides with N-acetylneuraminosyl ( $\alpha 2-6)$ lactosamine structure in primary human hepatoma. Cancer Res. 54, 1284-1290.

12) Taki, T., Rokukawa, C., Kasama, T. and Handa, S. (1992) Human hepatoma gangliosides.-Occurrence of a novel I-type glycolipid with NeuAc $\alpha 2-6 \mathrm{Gal}$ structure-. Cancer Res. 52, 4805-4811.

13) Hamasaki, H., Aoyagi, M., Kasama, T., Handa, S., Hirakawa, K. and Taki, T. (1999) GT1b in human metastatic brain tumors: GT1b as a brain metastasis-associated ganglioside. Biochim. Biophys. Acta 1437, 93-99.

14) Bolot, G., David, M., Kasama, T., Taki, T., Handa, S., Richard, M., Pignat, J., Thomas, L. and Portoukalian, J. (1999) Occurrence of monosialosyl penta hexosylceramide GalNAc- $\mathrm{GM}_{1}$ as specific tumor-associated ganglioside of human head and neck adenocarcinomas. Cancer Lett. 135, 159-164.

15) Taki, T., Kimura, H., Gasa, S., Nakamura, M. and Matsumoto, M. (1985) A new type of blood group $\mathrm{B}$ active glycosphingolipid in rat bone marrow cells.-Occurrence of the glycolipid in rat immunocytes and ascites hepatoma-. J. Biol. Chem. 260, 6219-6225.

16) Taki, T., Takagi, K., Kamada, R., Matsumoto, M. and Kojima, K. (1981) Study of asialogangliosides on surface membrane of rat bone marrow cells and macrophages. J. Biochem. 90, 1653-1660.

17) Taki, T., Kamada, R. and Matsumoto, M. (1982) Glycosphingolipid biosynthesis through asialogangliosides in rat bone marrow cells. J. Biochem. 91, 665-674.

18) Hakomori, S. (1983) Tumor-associated glycolipid antigens defined by monoclonal antibodies. Bull. Cancer 70, 118-126.

19) Tai, T., Cahan, L.D., Paulson, J.C., Saxton, R.E. and Irie, R.F. (1984) Human monoclonal antibody against ganglioside GD2: use in development of enzyme-linked immunosorbent assay for the monitoring anti-GD2 in cancer patients. J. Natl. Cancer Inst. 73, 627-633.

20) Myoga, A., Taki, T., Arai, K., Sekiguchi, K., Ikeda, I., Kurta, K. and Matsumoto, M. (1988) Detection of patients with cancer by monoclonal antibody directed to lactoneotetraosylceramide (paragloboside). Cancer Res. 48, 1512-1516.

21) Takamiya, K., Yamamoto, A., Furukawa, K., Yamashiro, S., Shin, M., Okada, M., Fukumoto, S., Haraguchi, M., Takeda, N., Fujimura, K., Sakae, M., Kishikawa, M., Shiku, H., Furukawa, K. and Aizawa, S. (1996) Mice with disrupted GM2/GD2 synthase gene lack complex gangliosides but exhibit only subtle defects in their nervous system. Proc. Natl. Acad. Sci. U.S.A. 93, 10662-10667.

22) Ishii, A., Ohta, M., Watanabe, Y., Matsuda, K., Ishiyama, K., Sakoe, K., Nakamura, M., Inokuchi, J., Sanai, Y. and Saito, M. (1998) Expression cloning and functional characterization of human cDNA for ganglioside GM3 synthase. J. Biol. Chem. 273, 31652-31655.

23) Ezoe, T., Vanier, M.T., Oya, Y., Popko, B., Tohyama, J., Matsuda, J., Suzuki, K. and Suzuki, K. (2000) Biochemistry and neuropathology of mice doubly deficient in synthesis and degradation of galactosylceramide. J. Neurosci. Res. 59, 170-178.

24) Scott, J.K. and Smith, G.P. (1990) Searching for peptide ligands with an epitope library. Science 249, 386-390.

25) Nishi, T., Budde, R.J., McMurray, J.S., Obeyesekere, N.U., Safdar, N., Levin, V.A. and Saya, H. (1996) Tight-binding inhibitory sequences against pp60 (c-src) identified using a random 15-amino-acid peptide library. FEBS Lett. 399, 237-240.

26) Taki, T., Ishikawa, D., Hamasaki, H. and Handa, S. (1997) Preparation of peptides which mimic glycosphingolipids by using phage peptide library and their modulation on $\beta$-galactosidase activity. 
FEBS Lett. 418, 219-223.

27) Taki, T., Ishikawa, D. and Handa, S. (1994) Blotting of glycolipids and phospholipids from a high performance thin-layer chromatogram to a polyvinylidene difluoride membrane. Anal. Biochem. 221, 312-316.

28) Taki, T., Ishikawa, D., Ogura, M., Nakajima, M. and Handa, S. (1997) GD1 $\alpha$ functions in the adhesion of metastatic tumor cells to endothelial cells of the target tissue. Cancer Res. 57, 1882-1888.

29) Taki, T., Hirabayashi, Y., Ishikawa, H., Ando, S., Kon, K., Tanaka, Y. and Matsumoto, M. (1986) A ganglioside of rat ascites hepatoma $\mathrm{AH} 7974 \mathrm{~F}$ cells.-Occurrence of a novel disialoganglioside $(\mathrm{GD} 1 \alpha)$ with a unique $\mathrm{N}$-acetylneuraminosyl $(\alpha 2$ 6)-N-acetylgalactosamine structure. J. Biol. Chem. 261, 3075-3078.

30) Taki, T., Maeda, H., Arai, K., Matsumoto, M., Kon, K. and Ando, S. (1988) Appearance of a novel of type of ganglioside (GD1 $\alpha$ ) in differentiation resistant clone of mouse myeloid leukemia cells M1-R1. Cell Struct. Funct. 13, 61-72.

31) Ishikawa, D., Kikkawa, H., Ogino, K., Hirabayashi, Y., Oku, N. and Taki, T. (1998) GD1 $\alpha$-replica peptides functionally mimic GD1 $\alpha$, an adhesion molecule of metastatic tumor cells, and suppress the tumor metastasis. FEBS Lett. 441, 20-24.

32) Takikawa, M., Kikkawa, H., Asai, T., Yamaguchi, N., Ishikawa, D., Tanaka, K., Ogino, K., Taki, T. and Oku, N. (2000) Suppression of GD1 $\alpha$ ganglioside-mediated tumor metastasis by liposomalized WHW-peptide. FEBS Lett. 466, 381-384.

33) Hakomori, S. (2001) Tumor associated carbohydrate antigens defining tumor malignancy; basis for development of anti-cancer vaccines. Adv. Exp. Med. Biol. 491, 369-402.

34) Hamamura, K., Furukawa, K., Hayashi, T., Hattori, T., Nakano, J., Nakashima, H., Okuda, T., Mizutani, H., Hattori, H., Ueda, M., Urano, T. and Lloyd, K. (2005) Ganglioside GD3 promotes cell growth and invasion through p130Cas and paxillin in malignant melanoma cells. Proc. Natl. Acad. Sci. U.S.A. 102, 11041-11046.

35) Kirkwood, J.M., Mascari, R.A., Edington, H.D., Rabkin, M.S., Day, R.S., Whiteside, T.L., Vlock, D.R. and Shipe-Spotloe, J.M. (2000) Analysis of therapeutic and immunologic effects of $\mathrm{R}_{24}$ antiGD3 monoclonal antibody in 37 patients with metastatic melanoma. Cancer 88, 2693-2702.

36) Scott, A.M., Lee, F.T., Hopkins, W., Cebon, J.S., Wheatley, J.M., Liu, Z., Smyth, F.E., Murone, C., Sturrock, S., MacGregor, D., Hanai, N., Inoue, K. Yamasaki, M., Brechbiel, M.W., Davis, I.D., Murphy, R., Hannah, A., Lim-Joon, M., Chan, T., Chong, T., Ritter, G., Hoffman, E.W., Burgess, A.W. and Old, L.J. (2001) Specific targeting, biodistribution, and lack of immunogenicity of chimeric anti-GD3 monoclonal antibody KM871 in patients with metastatic melanoma: results of a phase I trial. J. Clin. Oncol. 19, 3976-3987.

37) Chapman, P.B., Williams, L., Salibi, N., Hwu, W.J., Krown, S.E. and Livingston, P.O. (2004) A phase
II trial comparing five dose levels of BEC2 antiidiotypic monoclonal antibody vaccine that mimics GD3 ganglioside. Vaccine 22, 2904-2909.

38) Popa, I., Ishikawa, D., Tanaka, M., Ogino, K., Portoukalian, J. and Taki, T. (2006) GD3-replica peptides selected from a phage peptide library induce a GD3 ganglioside antibody response. FEBS Lett. 580, 1398-1404.

39) Taki, T., Ishikawa, D., Ogino, K., Tanaka, M., Oku, N., Asai, T., Popa, I. and Portoukalian, J. (2008) A new approach for drug discovery from glycobiology and phage-displayed peptide library technology. Biochim. Biophys. Acta 1780, 497-503.

40) Yuki, N., Handa, S., Taki, T., Kasama, T., Takahashi, M., Saito, K. and Miyatake, T. (1992) Cross-reactive antigen between nervous tissue and a bacterium elicits Guillain-Barré syndrome: Molecular mimicry between ganglioside GM1 and lipopolysaccharide from Penner's serotype 19 of Campylobacter jejuni. Biom. J. 13, 451-455.

41) Yuki, N., Taki, T., Inagaki, F., Kasama, T. Takahashi, M., Saito, K., Handa, S. and Miyatake, T. (1993) A bacterium lipopolysaccharide that elicits Guillain-Barré syndrome has a GM1 ganglioside-like structure. J. Exp. Med. 178, 17711775 .

42) Yuki, N., Taki, T., Takahashi, M. and Miyatake, T. (1994) Penner's serotype 4 of Campylobacter jejuni has a lipopolysaccharide that bears a GM1 ganglioside epitope as well as one that bears a GD1a epitope. Infect. Immun. 62, 2101-2103.

43) Yuki, N., Taki, T., Takahashi, M. and Miyatake, T. (1994) Molecular mimicry between GQ1b ganglioside and lipopolysaccharide of Campylobacter jejuni isolated from patients with Fisher's syndrome. Ann. Neurol. 36, 791-793.

44) Ilyas, A.A., Cook, S.D., Mithen, F.A., Taki, T., Kasama, T., Handa, S., Hamasaki, H., Singhal, B.S., Li, S.-C. and Li, Y.-T. (1998) Antibodies to $\mathrm{GT}_{1}$ a ganglioside in patients with Guillain-Barré syndrome. J. Neuroimmunol. 82, 160-167.

45) Yuki, N., Taki, T. and Handa, S. (1996) Antibody to GalNAc-GD1a and GalNAc-GM1b in GuillainBarré syndrome subsequent to Campylobacter jejuni enteritis. J. Neuroimmunol. 71, 155-161.

46) Yuki, N., Handa, S., Tai, T., Takahashi, M., Saito, K., Tsujino, Y. and Taki, T. (1995) Gangliosidelike epitopes of lipopolysaccharide from Campylobacter jejuni (PEN 19) in three isolates from patients with Guillain-Barré syndrome. J. Neurol. Sci. 130, 112-116.

47) Usuki, S., Thompson, S.A., Rivner, M.H., Taguchi, K., Shibata, K., Ariga, T. and Yu, R.K. (2006) Molecular mimicry: sensitization of Lewis rats with Campylobacter jejuni lipopolysaccharide induces formation of antibody toward GD3 ganglioside. J. Neurosci. Res. 83, 274-284.

48) Willers, J., Lucchese, A., Kanduc, D. and Ferrone, S. (1999) Molecular mimicry of phage displayed peptides mimicking GD3 ganglioside. Peptides 20, 1021-1026.

49) Usuki, S., Taguchi, K., Gu, Y.-H., Thompson, S.A. 
and Yu, R.K. (2010) Development of a novel therapy for lipo-oligosaccharide-induced experimental neuritis: use of peptide glycomimics. J. Neurochem. 113, 351-362.

50) Towbin, H., Schoenenberger, C., Ball, R., Braun, D.G. and Rosenfelder, G. (1984) Glycosphingolipid-blotting: an immunological detection procedure after separation by thin layer chromatography. J. Immunol. Methods 72, 471-479.

51) Taki, T., Kasama, T., Handa, S. and Ishikawa, D. (1994) A simple and quantitative purification of glycosphingolipids and phospholipids by thin-layer chromatography blotting. Anal. Biochem. 223, 232-238.

52) Korhonen, T.K., Väisänen, V., Saxén, H., Hultberg, H. and Svenson, S.B. (1982) P-antigen-recognizing fimbriae from human uropathogenic Escherichia coli strains. Infect. Immun. 37, 286-291.

53) Svenson, S.B., Hultberg, H., Källenius, G., Korhonen, T.K., Möllby, R. and Winberg, J. (1983) P-fimbriae of pyelonephritogenic Escherichia coli: identification and chemical characterization of receptors. Infection 11, 61-67.

54) Teneberg, S., Willemsen, P.T., de Graaf, F.K. and Karlsson, K.A. (1993) Calf small intestine receptors for K99 fimbriated enterotoxigenic Escherichia coli. FEMS Microbiol. Lett. 109, 107-112.

55) Smit, H., Gaastra, W., Kamerling, J.P., Vliegenthart, J.F. and de Graaf, F.K. (1984) Isolation and structural characterization of the equine erythrocyte receptor for enterotoxigenic Escherichia coli K99 fimbrial adhesin. Infect. Immun. 46, 578-584.

56) Isobe, T., Naiki, M., Handa, S. and Taki, T. (1996) A simple assay method for bacterial binding to glycosphingolipids on a polyvinylidene difluoride membrane after thin-layer chromatography blotting and in situ mass spectrometric analysis of the ligands. Anal. Biochem. 236, 35-40.

57) Ishikawa, D., Kato, T., Handa, S. and Taki, T. (1995) New methods using polyvinylidene difluoride membranes to detect enzymes involved in glycosphingolipid metabolism. Anal. Biochem. 230, 13-19.

58) Taki, T. and Chatterjee, S. (1995) An improved assay method for the measurement and detection of sphingomyelinase activity. Anal. Biochem. 224, 490-493.

59) Bogdanov, M., Sun, J., Kaback, H.R. and Dowhan, W. (1996) A phospholipid acts as a chaperone in assembly of a membrane transport protein. J. Biol. Chem. 271, 11615-11618.

60) Sun, J., Wu, J., Carrasco, N. and Kaback, H.R. (1996) Identification of the epitope for monoclonal antibody 4B1 which uncouples lactose and proton translocation in the lactose permease of Escherichia coli. Biochemistry 35, 990-998.

61) Kushi, Y. and Handa, S. (1985) Direct analysis of lipids on thin layer plates by matrix-assisted secondary ion mass spectrometry. J. Biochem. 98, 265-268.

62) Taki, T., Ishikawa, D., Handa, S. and Kasama, T.
(1995) Direct mass spectrometric analysis of glycosphingolipid transferred to a polyvinylidene difluoride membrane by thin-layer chromatography blotting. Anal. Biochem. 225, 24-27.

63) Kasama, T., Hisano, Y., Nakajima, M., Handa, S. and Taki, T. (1996) Microscale analysis of glycosphingolipids by TLC-blotting/secondary mass spectrometry: A novel blood group, A-active glycosphingolipids, and changes in glycosphingolipids expression in rat mammary tumor cells with different metastatic potentials. Glycoconj. J. 13, 461-469.

64) Harris, J.P. and Ryan, A.F. (1995) Fundamental immune mechanisms of the brain and inner ear. Otolaryngol. Head Neck Surg. 112, 639-653.

65) McCabe, B.F. (1979) Autoimmune sensorineural hearing loss. Ann. Otol. Rhinol. Laryngol. 88, 585-589.

66) Kanzaki, J. and O-Uchi, T. (1983) Circulating immune complexes in steroid-responsive sensorineural hearing loss and the long-term observation. Acta Otolaryngol. 393 (Suppl.), 77-84.

67) Brookes, G.B. (1986) Circulating immune complexes in Meniere's disease. Arch. Otolaryngol. Head Neck Surg. 112, 536-540.

68) Kataoka, H., Takeda, T., Nakatani, H. and Saito, H. (1995) Sensorineural hearing loss of suspected immune etiology: a report of these cases. Auris Nasus Larynx 22, 53-58.

69) Huhes, G.B., Kinney, S.E., Barna, B.P. and Calabrese, L.H. (1984) Practical versus theoretical management of autoimmune inner ear disease. Laryngoscope 94, 758-767.

70) Futaki, T., Yamane, M., Shirahata, A., Ohta, T. and Hirai, K. (1985) Immunological analysis of IgG and other protein fractions in endolymph obtained from endolymphatic sac of Meniere patients and control. Acta Otolaryngol. 419 (Suppl.), 71-78.

71) Terayama, T. and Sasaki, Y. (1964) Endolymphatic hydrops and III type allergic-reaction. Ear Res. Jpn. 58, 49-64.

72) Harada, T., Matsunaga, T., Hong, K. and Inoue, K. (1983) Endolymphatic hydrops in guinea pig. Science 222, 65-67.

73) Tomiyama, S., Kinoshita, T., Jinnouchi, K., Ikezono, T., Gotoh, Y., Pawanker, R. and Yagi, T. (1995) Fluctuating hearing loss following immune reaction in the endolymphatic sac of guinea pig. ORL $\mathbf{5 7}, 122-128$.

74) Ikeda, A., Komatsuzaki, A., Kasama, T., Handa, S. and Taki, T. (2000) Detection of antibody to sialyl$\mathrm{i}$, a possible antigen in patients with Meniere's disease. Biochim. Biophys. Acta 1501, 81-90.

75) Taki, T. and Ishikawa, D. (1997) TLC blotting: Application to microscale analysis of lipids and as a new approach to lipid-protein interaction. Anal. Biochem. 251, 135-143.

76) Goto-Inoue, N., Hayasaka, T., Taki, T., ValdesGonzalez, T. and Setou, M. (2009) A new lipidomics approach by thin-layer chromatography-blot-matrix-assisted laser desorption/ionization imaging mass spectrometry for analyzing 
detailed patterns of phospholipid molecular species. J. Chromatogr. A 1216, 7096-7101.

77) Goto-Inoue, N., Hayasaka, T., Sugiura, Y., Taki, T. Li, Y.T., Matsumoto, M. and Setou, M. (2008) High-sensitivity analysis of glycosphingolipids by matrix-assisted laser desorption/ionization quadrupole ion trap time-of-flight imaging mass spectrometry on transfer membranes. J. Chromatogr. B Analyt. Technol. Biomed. Life Sci. 870, 74-83.

78) Valdes-Gonzalez, T., Goto-Inoue, N., Hayasaka, T., Ishiyama, H., Setou, M. and Taki, T. (2011) Imaging technology of complex lipid molecular species by a combination of TLC-Blot and MALDI-TOF MS. Special reference to human brain ganglioside molecular species. J. Glycom. Lipidom. 1, 1-6.

79) Valdes-Gonzalez, T., Goto-Inoue, N., Hirano, W., Ishiyama, H., Hayasaka, T., Ishiyama, H., Setou, M. and Taki, T. (2011) New approach for glycoand lipidomics - Molecular scanning of human brain gangliosides by TLC-Blot and MALDI-QITTOF MS. J. Neurochem. 116, 678-683.

80) Rosenberg, A. and Stern, N. (1966) Changes in sphingosine and fatty acid components of the gangliosides in developing rat and human brain. J. Lipid Res. 7, 122-131.

81) Palestini, P., Masserini, M., Sonnino, S., Giuliani, A. and Tettamanti, G. (1990) Changes in the ceramide composition of rat forebrain gangliosides with age. J. Neurochem. 54, 230-235.

82) Valsecchi, M., Palestini, P., Chigorno, V. and Sonnino, S. (1996) Age-related changes of the ganglioside long-chain base composition in rat cerebellum. Neurochem. Int. 28, 183-187.

83) Sonnino, S. and Chigorno, V. (2000) Ganglioside molecular species containing C18- and C20-sphingosine in mammalian nervous tissues and neuronal cell cultures. Biochim. Biophys. Acta 1469, 63-77.

84) Sugiura, Y., Shinma, S., Konishi, Y., Yamada, M.K. and Setou, M. (2008) Imaging mass spectrometry technology and application on ganglioside study; visualization of age-dependent accumulation of C20-ganglioside molecular species in the mouse hippocampus. PLoS ONE 3, e3232.

85) Taki, T. (2012) An approach to glycobiology from glycolipidomics - Ganglioside molecular scanning in the brains of patients with Alzheimer's disease by TLC-Blot/MALDI-TOF MS. Biol. Pharm. Bull. 35, 1642-1647.

86) Shin, R.W., Ogino, K., Shimabuku, A., Taki, T., Nakashima, H., Ishihara, T. and Kitamoto, T. (2007) Amyloid precursor protein cytoplasmic domain with phospho-Thr668 accumulates in Alzheimer's disease and its transgenic models; a role to mediate interaction of $\mathrm{A} \beta$ and tau. Acta Neuropathol. 113, 627-636.

87) Goto-Inoue, N., Hayasaka, T., Zaima, N. and Setou, M. (2011) Imaging mass spectrometry for lipidomics. Biochim. Biophys. Acta 1811, 961-969.

88) Veloso, A., Fernández, R., Astigarraga, E., BarredaGómez, G., Manuel, I., Giralt, M.T., Ferrer, I., Ochoa, B., Rodríguez-Puertas, R. and Fernández, J.A. (2011) Distribution of lipids in human brain. Anal. Bioanal. Chem. 401, 89-101.

89) Goto-Inoue, N., Hayasaka, T., Zaima, N. and Setou, M. (2009) The specific localization of seminolipid molecular species on mouse testis during testicular maturation revealed by imaging mass spectrometry. Glycobiology 19, 950-957.

90) Jackson, S.N. and Woods, A.S. (2009) Direct profiling of tissue lipids by MALDI-TOF MS. J. Chromatogr. B Analyt. Technol. Biomed. Life Sci. 877, 2822-2829.

91) Taki, T., Valdes-Gonzalez, T., Goto-Inoue, N., Hayasaka, T. and Setou, M. (2009) TLC blot (far-eastern blot) and its applications. Methods Mol. Biol. 536, 545-556.

(Received Apr. 9, 2013; accepted May 10, 2013) 


\section{Profile}

Takao Taki was born in Shizuoka, Japan in 1943. He graduated from Shizuoka College of Pharmacy in 1966, and received Ph.D. (1975) degree. He started his professional research career as a Research Associate in Department of Biochemistry, Applied Medical Science Institute, School of Medicine, Shinshu University in 1966. Then, he moved to the Department of Biochemistry, Shizuoka College of Pharmacy in 1967. From 1976 to 1978, he worked as a Research Associate in the Department of Biochemistry, School of Medicine, University of Manitoba, Canada, where he engaged in the separation of phospholipase D and base exchange reaction enzymes in rat brain. In 1988, he moved to the Department of Molecular Medical Chemistry, Tokyo Medical and Dental University, as an Associate Professor. In 1997, he was invited as a Director

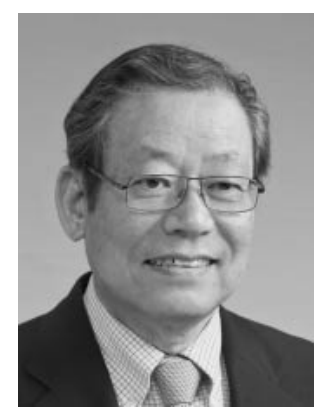
General of Cellular Technology Institute, Otsuka Pharmaceutical Co. Ltd., and he worked as a Director of the Molecular Medical Science Institute, Otsuka Pharmaceutical Co. Ltd. from 1999 to 2007. He is in the position of Scientific Advisor of the same company from 2007.

His research was started from the finding and separation of phospholipid metabolizing enzymes, phospholipase D and base exchange reaction enzymes in animal tissues. After coming back to Shizuoka College of Pharmacy from University of Manitoba, his research was focused on the glycosphingolipid metabolism and functions in tumor. He found glycosphingolipid biosynthetic pathway leading to GD1 $\alpha$ through asialogangliosides and GM1b in the series of this research. By introducing a technology of phage displayed peptide library, he demonstrated new approach to glycobiology. TLC-Blot demonstrated in this review brought about a new lipidomics by a combination with MALDI-TOF MS. 